\title{
Reaction-Dependent Heteroatom Modification of Acid-Base Catalytic Cooperativity in Aminosilica Materials
}

\author{
Eric G. Moschetta, Nicholas A. Brunelli, and Christopher W. Jones \\ School of Chemical \& Biomolecular Engineering \\ Georgia Institute of Technology
}

311 Ferst Drive NW

Atlanta, GA 30332 


\begin{abstract}
The effects of heteroatom substitution on the cooperative catalytic activity of a series of bifunctional acid-base aminosilica catalysts are probed in aldol and nitroaldol condensations. Three $\mathrm{M}^{3+}(\mathrm{B}, \mathrm{Al}$, and $\mathrm{Ga})$ and three $\mathrm{M}^{4+}(\mathrm{Ti}, \mathrm{Zr}$, and $\mathrm{Ce})$ heteroatoms are incorporated into different samples of SBA-15 silica and then grafted with aminosilanes to produce bifunctional acid-base catalysts. The catalytic activity of each material is measured in the aldol condensation of 4-nitrobenzaldehyde with acetone at $50{ }^{\circ} \mathrm{C}$ and the nitroaldol condensation of 4nitrobenzaldehyde with nitromethane at $40{ }^{\circ} \mathrm{C}$ and compared to the catalytic activity of a heteroatom-free aminosilica catalyst. The heteroatom substitutions produce catalysts with larger amounts of strong Lewis acid sites compared to the heteroatom-free aminosilica catalyst. We rationalize these results in the context of the physical (e.g. surface area, pore diameter, particle size) and chemical properties (e.g. total number and strength of acid sites) of each material and the proposed catalytic mechanisms of the two reactions. The increase in the number of strong Lewis acid sites of each heteroatom material decreased its activity in the aldol condensation, though four heteroatom substitutions $(\mathrm{B}, \mathrm{Al}, \mathrm{Ga}$, and $\mathrm{Ti})$ increased the catalytic activity of the aminosilica catalyst in the nitroaldol condensation. The results suggest inclusion of a small amount of Lewis acid sites in aminosilica materials can increase the cooperative catalytic activity of the materials in the nitroaldol condensation. The results also suggest inclusion of Lewis acid sites in aminosilica materials decreases the cooperative catalytic activity of the materials in the aldol condensation.
\end{abstract}

Keywords: Cooperative Catalysis; Aminosilica; Heteroatom; Brønsted Acid; Lewis Acid 


\section{Introduction}

Cooperative catalytic activity can be achieved in a variety of ways and can be defined as the interaction between two distinct catalytic sites to achieve a rate of reaction that is greater than the rate achieved with a single component [1]. Such reactions can be achieved with bifunctional catalysts that contain two distinct functional groups, most commonly an acid and a base, that are spatially separated such that the functional groups do not interfere with each other, yet can interact with a substrate(s) cooperatively to increase the rate of reaction. The two distinct catalytic units can individually activate substrates or act in concert to enhance the reaction, among other modes of cooperative activation [1]. The design of bifunctional catalysts most often relies on combining simple, inexpensive catalytic elements on chemically functionalizable materials to enable cooperative interactions [2,3]. Examples of cooperative acid-base catalysts include homogeneous organocatalysts [4-8], polymeric systems [9], carbon quantum dots [10], and silica immobilized systems [11-19]. The facile ability to separate and recycle heterogeneous catalysts from reactive fluids makes them attractive targets for incorporating acid-base cooperativity in new materials. While the results from homogeneous catalysts can be used as a basis for designing heterogeneous catalysts, incorporating cooperative catalytic elements is considerably more challenging in heterogeneous systems such as those based on silica supports because the silanols present on the surface, which act as organic functional group anchoring points or as weakly acidic cooperative partners, are typically not uniformly distributed [20-26]. Despite the complexity of silica-based catalysts, numerous studies demonstrate the ability to design materials that exhibit cooperative interactions, providing considerable insight into optimizing such catalysts. Early indications that silanols could act cooperatively with amines 
were unambiguously defined through experiments using thermally cleavable protecting groups and capping the surface silanols with trimethylsilyl groups using hexamethyldisilazane (HMDS) [27-31]. More recently, immobilizing amines with different linker lengths demonstrated that spatial positioning of the amines with respect to the location of surface silanols was crucial to optimizing the amine-silanol cooperativity [3,19]. While many types of acidic species including sulfonic, phosphoric and carboxylic acids have been used as cooperative partners $[11,12,18]$, it was recently demonstrated that weaker acidic species, such as silanols, provided more favorable cooperative interactions in the form of superior catalytic activity for the aldol condensation of 4nitrobenzaldehyde with acetone in comparison to carboxylic acids and other stronger acids [18]. Another study revealed that shorter alkyl tethers (e.g. methyl and ethyl) limited cooperative interactions whereas alkyl linkers longer than propyl exhibited the same catalytic rate for the aldol condensation of 4-nitrobenzaldehyde with acetone [19]. Additionally, the choice of solvent can impact the activity of the bifunctional catalyst. A recent report demonstrated that primary amines tethered to silica were more active for the aldol condensation of acetone and 4nitrobenzaldehyde in water than in hexane because water shifted the equilibrium in favor the aldol product and prevented the amine from forming an imine with 4-nitrobenzaldehyde, which inhibited the reaction [32].

In an interesting finding, it was recently shown that the observed trend for the alkyl linker lengths differs depending on the specific reactions. For the nitroaldol (Henry) condensation of 4nitrobenzaldehyde with nitromethane, the rate of reaction steadily increased with increasing alkyl linker length on SBA-15 silica with a pore diameter of $6.5 \mathrm{~nm}$ [3]. Furthermore, that study also demonstrated that changing the pore diameter of the silica varied the catalytic activity by as much as an order of magnitude for the nitroaldol condensation, while also shifting the 
distribution of optimal amine linker lengths, providing another method for tuning the aminesilanol cooperative interactions [3].

These previous studies have mainly focused on modifying the organic components of the catalytic moieties and the physical dimensions of the silica support, though the chemical modification of the silica framework may also have positive effects on the activity of cooperative catalysts. Additionally, these previous studies primarily used the surface silanols as the acidic component of the cooperative interactions, but the inherent heterogeneity of the distribution of silanols present on the surface makes controlling the number of protic species with which the amines interact difficult. An alternative method to modify the properties of the silanol-covered surface is the incorporation of heteroatoms in the silica matrix. $\mathrm{M}^{3+}$ elements will typically introduce a Brønsted acid site that is a stronger acid than the silanols, while $\mathrm{M}^{4+}$ elements will introduce new types of hydroxyl species such as titanols [33] or even Lewis acidic sites in the case of coordinatively unsaturated $\mathrm{Zr}^{4+}$ species [34,35] and tetrahedrally coordinated $\mathrm{Ti}$ sites [36]. At present, studies of the effects of heteroatom substitution on cooperative acid-base catalysts have been limited mainly to Al substitution for C-C coupling reactions and one-pot cascade reactions $[13,37-48]$. In this study, we examine the effects of heteroatom substitution with materials with similar pore diameters, similar organic (amine) loadings, and approximately $5 \mathrm{~mol} \%$ heteroatom substitution. More specifically, we investigate the effects of heteroatom substitution for two well-studied model reactions (aldol vs. nitroaldol couplings), showing these reactions are differently affected by the incorporation of heteroatoms into the silica framework.

\section{Experimental}

\subsection{Materials}


Pluronic P123 block copolymer $\left(\mathrm{EO}_{20} \mathrm{PO}_{70} \mathrm{EO}_{20}, \mathrm{M}_{\mathrm{n}} \sim 5,800\right)$, tetraethyl orthosilicate (TEOS, 98\%), tetramethyl orthosilicate (TMOS, 98\%), aluminum isopropoxide $\left(\mathrm{Al}\left(\mathrm{O}^{i} \mathrm{Pr}\right)_{3}\right.$, 98\%), titanium tetraisopropoxide $\left(\mathrm{Ti}\left(\mathrm{O}^{i} \mathrm{Pr}\right)_{4}, \quad 98 \%\right)$, cerium(III) nitrate hexahydrate $\left(\mathrm{Ce}\left(\mathrm{NO}_{3}\right)_{3} \cdot 6 \mathrm{H}_{2} \mathrm{O}, 99 \%\right)$, zirconium oxychloride octahydrate $\left(\mathrm{ZrOCl} \cdot 8 \mathrm{H}_{2} \mathrm{O}, 98 \%\right)$, ammonium

fluoride $\left(\mathrm{NH}_{4} \mathrm{~F}, 98 \%\right)$, and nitromethane (96\%) were obtained from Sigma-Aldrich. Acetone (99.5\%), aqueous ammonia (28 wt \% $\mathrm{NH}_{3}$ ) and 4-nitrobenzaldehyde (99\%) were obtained from Alfa Aesar. Toluene (99.5\%) and hexane (98.5\%) were obtained from BDH. Ethanol (100\%) was obtained from Koptec, (3-aminopropyl)triethoxysilane (99\%) was obtained from Gelest, 1,4dimethoxybenzene (99\%) was obtained from TCI, and 12.1 M HCl was obtained from EMD. Deuterated chloroform (99.8\%) was obtained from Cambridge Isotope Laboratories, Inc.

\subsection{Synthesis of SBA-15 and Heteroatom-Substituted SBA-15}

All SBA-15 materials were prepared according to previous reports [18,19,37,49-55]. The details of the synthetic procedures are in the Supporting Information.

\subsection{Grafting of Organosilanes on SBA-15 Materials}

For each heteroatom material and bare SBA-15 silica, a $500 \mathrm{mg}$ sample was dried under vacuum at $100{ }^{\circ} \mathrm{C}$ overnight prior to functionalization. The flask containing the $500 \mathrm{mg}$ sample was purged with UHP nitrogen and mixed with $12.5 \mathrm{~mL}$ of anhydrous toluene and $58.5 \mu \mathrm{L}$ of (3aminopropyl)triethoxysilane (or $67.2 \mu \mathrm{L}$ of (5-aminopentyl)triethoxysilane synthesized in a Parr reactor from the reaction of 5-bromopentyl triethoxysilane with ammonia) [19]. The solution of toluene and silane was injected via syringe through the rubber septum of the flask, at which point the mixture was magnetically stirred at room temperature for $24 \mathrm{~h}$. Next, the mixture was heated 
to $80{ }^{\circ} \mathrm{C}$ and stirred for another $24 \mathrm{~h}$. The solid was washed and filtered with $100 \mathrm{~mL}$ each of toluene, hexane, and ethanol, sequentially. The material was dried under vacuum at $100{ }^{\circ} \mathrm{C}$ overnight and stored in a labeled container for later use. Amine-functionalized heteroatom materials follow the same naming convention, $\mathrm{X}-\mathrm{A \# -SBA-15}$, in this manuscript, where $\mathrm{X}$ refers to the heteroatom and $\mathrm{A \#}$ refers to the number of carbon atoms in the alkylamine linker (A1 for aminomethyl, A3 for aminopropyl, A5 for aminopentyl). The amine-functionalized SBA-15 without heteroatom substitution is called A3-SBA-15 throughout the manuscript.

\subsection{Materials Characterization}

Nitrogen physisorption experiments were performed on a Micromeritics Tristar 2030 at 77 K. All samples (approximately $100 \mathrm{mg}$ each) were degassed under vacuum overnight at 110 ${ }^{\circ} \mathrm{C}$ prior to the physisorption measurements. The surface area of each material was determined using the Brunauer-Emmett-Teller (BET) method and the total pore volume and pore diameter was determined using the Broekhoff-de Boer method with the Frenkel-Halsey-Hill (BdB-FHH) modification using the data from the adsorption isotherm [56]. Scanning electron microscopy (SEM) images were recorded on a Hitachi scanning electron microscope (SEM SU 8010) using an acceleration voltage of $5 \mathrm{kV}$. A thin layer of gold was sputtered onto each sample prior to scanning. Ammonia temperature programmed desorption (TPD) experiments were performed on

a Micromeritics Autochem II 2920. Approximately $125 \mathrm{mg}$ of each sample was placed into a quartz U-tube and dried under a flow of $\mathrm{He}$ at $10 \mathrm{~mL} / \mathrm{min}$ at $500{ }^{\circ} \mathrm{C}$ for $1 \mathrm{~h}$. Each sample was cooled to $50{ }^{\circ} \mathrm{C}$, at which point $\mathrm{NH}_{3}(2000 \mathrm{ppm}$ in He) flowed over the sample at a rate of 25 $\mathrm{mL} / \mathrm{min}$ for $1 \mathrm{~h}$. The sample was held at $50{ }^{\circ} \mathrm{C}$ while the tube was purged with $\mathrm{He}$ for 30 min to remove weakly adsorbed $\mathrm{NH}_{3}$. The desorption experiment started at $50{ }^{\circ} \mathrm{C}$ and increased to 500 
${ }^{\circ} \mathrm{C}$ in a He flow of $10 \mathrm{~mL} / \mathrm{min}$ with a temperature increase of $10{ }^{\circ} \mathrm{C} / \mathrm{min}$. The desorbed $\mathrm{NH}_{3}$ was measured by a thermal conductivity detector (TCD). All samples containing organosilanes were sent to Atlantic Microlab (Norcross, GA) for elemental analysis (EA) of the nitrogen content of each sample while all samples containing heteroatoms were sent to Galbraith Laboratories, Inc. (Knoxville, TN) for EA for the heteroatom content. X-ray diffraction (XRD) experiments were performed on a PAnalytical X'Pert diffractometer using a $\mathrm{Cu} \mathrm{K} \alpha$ source. Each sample was placed on a sample holder using a parallel plate detector scanning from $2 \theta$ of $0.6-3^{\circ}$ with an incident grazing angle of $1^{\circ}$ and a step size of $0.02^{\circ}$. Solid-state NMR spectra were recorded on a Bruker Avance III 400 spectrometer at a sample spinning speed of $12 \mathrm{kHz}$. Samples were hydrated prior to running the NMR experiments. Liquid-phase ${ }^{1} \mathrm{H}$ NMR experiments were conducted on a Varian Mercury Vx 400. Diffuse reflectance UV-Vis spectra were recorded on a Cary UV-Vis 500 using an internal reflectance cell and pure SBA-15 as the background. Pyridine IR experiments were conducted on a Thermo Scientific Nicolet 8700 FTIR Spectrometer equipped with an MCT/A detector. Samples were pressed into wafers and placed in a stainless steel UHV chamber sealed with a fresh copper gasket and evacuated at $200{ }^{\circ} \mathrm{C}$ for $1 \mathrm{~h}$. The temperature of the cell was decreased to $50{ }^{\circ} \mathrm{C}$, at which point pyridine was admitted to the cell at a pressure of $0.1 \mathrm{mbar}$ and allowed to equilibrate for at least $20 \mathrm{~min}$, followed by evacuation for $1 \mathrm{~h}$ to remove physisorbed pyridine. Next, the IR spectrum of the sample was recorded to ensure the pyridine was chemisorbed to the acid sites prior to the desorption experiments. The temperature of the cell was increased to $100{ }^{\circ} \mathrm{C}$ and held for $1 \mathrm{~h}$, then decreased to $50{ }^{\circ} \mathrm{C}$ and held for $10 \mathrm{~min}$, then increased to $200{ }^{\circ} \mathrm{C}$ for $1 \mathrm{~h}$, then decreased again to $50{ }^{\circ} \mathrm{C}$. Spectra were recorded every $5 \mathrm{~min}$. Each spectrum consisted of 64 scans at a resolution of $4 \mathrm{~cm}^{-1}$. The total amounts of acid sites for each material were obtained using the integrated peak 
areas (Brønsted sites near $1540 \mathrm{~cm}^{-1}$, Lewis sites near $1450 \mathrm{~cm}^{-1}$ ) and molar extinction coefficients for Brønsted acid sites $(1.8 \mathrm{~cm} / \mu \mathrm{mol})$ and Lewis acid sites $(1.3 \mathrm{~cm} / \mu \mathrm{mol})$ from the literature $[46,57,58]$.

\subsection{Catalytic Measurements}

All reactions were performed in $25 \mathrm{~mL}$ two-neck roundbottom flasks under pressure of UHP nitrogen, each fitted with a condenser, magnetic stir bar, and rubber septum. Stock solutions for the aldol and nitroaldol condensations were prepared in advance and stored in a refrigerator prior to use. Each solution consisted of $604.5 \mathrm{mg}$ 4-nitrobenzaldehyde, $552.6 \mathrm{mg}$ 1,4dimethoxybenzene as an internal standard, and either $80 \mathrm{~mL}$ of acetone (for the aldol condensation) or $80 \mathrm{~mL}$ of nitromethane (for the nitroaldol condensation) as the reactant in excess, also acting as the solvent. For each reaction, $1.0025 \mathrm{~mL}$ of the stock solution was added to the flask, removing $25 \mu \mathrm{L}$ as the initial sample for $\mathrm{GC}$ analysis. Next, the supported catalyst was added to the flask such that $10 \mathrm{~mol} \%$ nitrogen $(0.005 \mathrm{mmol})$ was present relative to the initial amount of 4-nitrobenzaldehyde $(0.05 \mathrm{mmol})$ in the flask. The flask was immersed in an oil bath at $50{ }^{\circ} \mathrm{C}$ for the aldol condensation and $40{ }^{\circ} \mathrm{C}$ for the nitrolaldol condensation, with magnetic stirring. Samples were withdrawn through the septum with a syringe every 15 min for 1 $\mathrm{h}$ and once an hour through $4 \mathrm{~h}$. All reaction samples were run through a short bed of silica gel in a cotton-plugged pipet to remove the catalyst and washed with acetone directly into a GC vial. GC samples were run on a Shimadzu GC-2010 equipped with a flame ionization detector (FID), an AOC-20i+s autoinjector and autosampler, and a Restek Rtx-5 GC column (15 m, 0.25 mm inner diameter, $0.1 \mu \mathrm{m}$ film thickness). Product selectivity was determined by ${ }^{1} \mathrm{H}$ NMR after $4 \mathrm{~h}$ 
of reaction time. The solutions were concentrated in vacuo and dissolved in deuterated chloroform.

\section{Results and Discussion}

\subsection{Physical Characterization of Materials}

The amino-silanol catalysts were successfully synthesized, each containing a series of different heteroatoms, including $\mathrm{M}^{3+}$ elements (B, $\mathrm{Al}, \mathrm{Ga}$ ) and $\mathrm{M}^{4+}$ elements ( $\mathrm{Ti}, \mathrm{Zr}, \mathrm{Ce}$ ). Nitrogen physisorption experiments showed that the pore diameters are approximately $7.5 \mathrm{~nm}$ (see Fig. 1 for the adsorption isotherms) in all cases. It is critical to maintain the same pore diameters among all catalysts because previous studies demonstrated that the pore diameter affects the cooperativity between the amines and surface silanols [3,59-63]. The amine functionalization procedure did not alter the pore diameter, indicating that the procedure was sufficiently mild. Table 1 contains the surface areas, cumulative pore volumes, pore diameters, and the average particle sizes of the six amine-functionalized heteroatom materials and A3-SBA15. Fig. S1 in the Supporting Information shows the SEM images for the amine-silanol catalysts. The particle morphologies differ between the catalysts, most likely due to the different synthesis conditions for each of the materials. The standard A3-SBA-15 material, along with the B-, Ga-, Ti-, and Ce-A3-SBA-15 materials, all exhibit similar rod-like morphologies. The Zr-A3-SBA-15 catalyst shows a spherical shape while the Al-A3-SBA-15 catalyst shows an irregular morphology.

Fig. 2 shows the XRD patterns for the six heteroatom materials compared to A3-SBA-15. In all cases, the large (100) diffraction peak appears from $2 \theta=0.6-1.2$ and the two smaller (110) and (200) diffraction peaks appear from $2 \theta=1.3-2.0$, verifying the retention of the expected 2D 
hexagonal mesoporous structure. For larger heteroatoms such as $\mathrm{Zr}$ and $\mathrm{Ce}$, the (110) and (200) diffraction peaks are also larger.

\subsection{Chemical Characterization of Materials}

Fig. 3 shows the $\mathrm{NH}_{3}$ TPD profiles for the A3-SBA-15 silica compared to the $\mathrm{M}^{3+}$ heteroatom materials and Fig. 4 shows the TPD profiles for the $\mathrm{M}^{4+}$ heteroatom materials. For A3-SBA-15, the TPD profile revealed a low temperature peak at $86{ }^{\circ} \mathrm{C}$ and a high temperature peak at $222{ }^{\circ} \mathrm{C}$. All six heteroatom substitutions produced materials with more total acid sites compared to the standard A3-SBA-15, because the total amount of adsorbed $\mathrm{NH}_{3}$ was higher in each case after heteroatom substitution. Heteroatoms of $\mathrm{M}^{3+}$ character can incorporate themselves tetrahedrally into the silica framework to introduce Brønsted acidity if proton balances the framework negative charge [64]. Additionally, $\mathrm{M}^{3+}$ cations may contribute Lewis acid sites to the overall framework when coordinatively unsaturated metal sites are present. The B-A3-SBA-15 and Al-A3-SBA-15 heteroatom materials exhibit sharp peaks at $95{ }^{\circ} \mathrm{C}$ and $99{ }^{\circ} \mathrm{C}$, respectively, while both materials have high temperature peaks at $300{ }^{\circ} \mathrm{C}$ (the peak area for BA3-SBA-15 is small). The Ga-A3-SBA-15 heteroatom material exhibits a sharp peak at $108{ }^{\circ} \mathrm{C}$ with a broad shoulder appearing after the low temperature peak and continuing to approximately $500{ }^{\circ} \mathrm{C}$. This broad shoulder for Ga-A3-SBA-15 indicates both a larger total number of acid sites and a range of acid strengths (addressed further below) for the $\mathrm{Ga}^{3+}$ cations dispersed throughout the silica. Palomino et al. synthesized MCM-41 silica doped with Ga and observed Brønsted and Lewis acidity via FTIR spectra of adsorbed pyridine and CO and attributed the Brønsted acidity to hydroxyls bridging $\mathrm{Si}$ and $\mathrm{Ga}$ atoms and Lewis acidity to coordinatively unsaturated $\mathrm{Ga}^{3+}$ ions [65]. Al-substituted SBA-15 materials exhibit Brønsted and Lewis acidity under the same 
conditions $[37,66]$. Eswaramoorthi and Dalai synthesized B-substituted SBA-15 and used ${ }^{11}$ B triple quantum magic-angle spinning (MAS) NMR to observe tri- and tetracoordinated B atoms in the silica matrix and diffuse reflectance infrared Fourier transform (DRIFT) spectroscopy to observe increased Brønsted and Lewis acidity as the degree of B substitution increased [67].

Among the $\mathrm{M}^{4+}$ heteroatom materials, the Ti-A3-SBA-15 and Ce-A3-SBA-15 heteroatom materials showed single peaks at $108{ }^{\circ} \mathrm{C}$ and $92{ }^{\circ} \mathrm{C}$, respectively, while Ti-A3-SBA-15 displayed a high temperature peak at $325{ }^{\circ} \mathrm{C}$. The $\mathrm{Zr}$-A3-SBA-15 heteroatom material exhibited a peak at $118^{\circ} \mathrm{C}$ and a broad shoulder afterward, all indicating an increased total number of acid sites for the heteroatom material compared to A3-SBA-15. Heteroatom substitutions in silica materials using $\mathrm{Ti}, \mathrm{Zr}$, and $\mathrm{Ce}$ as the heteroatoms are known to contribute Lewis acidity to the overall material [53-55,68]. For $\mathrm{Zr}$ substitutions, it is possible to observe Brønsted acidity as well [53]. $\mathrm{Zr}$ substitutions in silica materials also introduce $\mathrm{Zr}-\mathrm{O}-\mathrm{Si}$ linkages, which may distort the silica structure and induce charge imbalances that are offset by weakening the existing $\mathrm{O}-\mathrm{H}$ bonds of the silanols in the vicinity of the $\mathrm{Zr}-\mathrm{O}-\mathrm{Si}$ linkage, thereby creating a slight increase of Brønsted acidity at these weakened silanols [69]. Ti substitutions in silica materials introduce Ti-O-Si linkages, which may require the charge balancing of tetrahedral $\mathrm{Si}$ and octahedral Ti through a hydroxyl group if water vapor is present [70,71]. Kataoka and Dumesic used Pauling's electrostatic valence rule to show the oxygen in a Ti-O-Si linkage was electronically undersaturated by 0.33 valence units (v.u.) if the Ti was octahedrally coordinated in the presence of water vapor, thereby creating a Brønsted acid site at the undersaturated oxygen [71]. Other reports state that tetrahedral Ti does not introduce Brønsted acid sites in silica-rich frameworks, as expected for $\mathrm{Ti}^{4+}$ substitution of silicon [70,72]. 
Table 2 contains the elemental analysis for the six amine-functionalized heteroatom materials and A3-SBA-15. The results indicate the incorporation of the heteroatom depended on the nature of the synthesis. In all cases, the amount of heteroatom present is less than the theoretical amount as outlined in the Experimental section of the Supporting Information for each material. However, the larger amounts of $\mathrm{Ga}$ and $\mathrm{Zr}$ merit further characterization to determine whether the heteroatoms truly are incorporated into the silica framework or if they are present as bulk oxide domains.

Fig. 5 shows the ${ }^{27} \mathrm{Al}$ solid-state NMR spectrum of Al-A3-SBA-15. The peak at $\sim 0 \mathrm{ppm}$ corresponds to octahedral $\mathrm{Al}$ and the peak at $\sim 54 \mathrm{ppm}$ corresponds to tetrahedral $\mathrm{Al}$ [66]. The integrated peak areas produce a ratio of 1.6 octahedral $\mathrm{Al}$ atoms to every tetrahedral $\mathrm{Al}$ atom, indicating more potentially Lewis-acidic Al was substituted into the silica framework than Brønsted acidic species. Fig. 6 shows the ${ }^{11}$ B solid-state NMR spectrum of B-A3-SBA-15. The peak at -3.4 ppm corresponds to tetrahedral B only, indicative of Brønsted acidity [67,73]. Fig. 7 shows the ${ }^{71} \mathrm{Ga}$ solid-state NMR spectrum of Ga-A3-SBA-15. The lone peak at $144 \mathrm{ppm}$ corresponds to tetrahedral Ga incorporated into the silica framework [74,75]. Okumura et al. synthesized Ga-substituted MCM-41 and observed a peak at -24 ppm that they attributed to octahedral $\mathrm{Ga}$ external to the silica structure, a peak that is absent in our sample [76]. Additionally, no peaks corresponding to bulk $\mathrm{Ga}_{2} \mathrm{O}_{3}$ domains appear (25 ppm, 40-56 ppm, 200 ppm), indicating that all Ga was incorporated into the silica framework [77-79].

Fig. 8 shows the diffuse reflectance UV-Vis spectra of Ti-A3-SBA-15, Zr-A3-SBA-15, and Ce-A3-SBA-15 materials. The aminopropyl-functionalized Ti heteratom material exhibited an absorption near $230 \mathrm{~nm}$, indicative of tetrahedral $\mathrm{Ti}$, and an absorption near $320 \mathrm{~nm}$, indicative of octahedral $\mathrm{Ti}[80,81]$. The Zr-A3-SBA-15 material exhibited an absorption near 
$195 \mathrm{~nm}$, which corresponds to isolated tetrahedral $\mathrm{Zr}$, and another absorption near $300 \mathrm{~nm}$, which corresponds to octahedral Zr [82]. Furthermore, the lack of a peak near $240 \mathrm{~nm}$ for the $\mathrm{Zr}$ A3-SBA-15 indicates there is no bulk $\mathrm{ZrO}_{2}$ on the silica surface [82]. Other reports confirm that isolated $\mathrm{Zr}^{4+}$ species absorb at shorter wavelengths (blue-shift) than bulk $\mathrm{Zr}^{4+}$ species because the bulk $\mathrm{Zr}^{4+}$ species exist in the monoclinic phase which has a lower ligand-to-metal charge-transfer (LCMT) energy compared to the isolated $\mathrm{Zr}^{4+}$ species [83-85]. The amine-functionalized Ce material exhibited an absorption near $300 \mathrm{~nm}$, indicative of tetracoordinated $\mathrm{Ce}^{4+}$ species in the silica framework, though the smaller peak near $240 \mathrm{~nm}$ is indicative of the presence of a small fraction of $\mathrm{Ce}^{3+}[54,55]$.

Fig. 9 shows the amount of adsorbed pyridine (confirming the presence of Brønsted and Lewis acid sites) in each of the heteroatom materials and the standard A3-SBA-15 material as determined by IR spectroscopy measurements, while the amounts of each type of acid site are listed in Table 3. IR spectra for all samples are located in the Supporting Information (Fig. S2S8). All six heteroatom materials had higher amounts of Lewis acid sites than Brønsted acid sites at all desorption temperatures. The A3-SBA-15 had weakly physisorbed pyridine near $1450 \mathrm{~cm}^{-1}$ at $50{ }^{\circ} \mathrm{C}$, but otherwise had no discernible Brønsted or Lewis acid sites at all desorption temperatures, in agreement with the literature [58]. With the exception of $\mathrm{Ce}$, higher loadings of heteroatoms led to materials with more total acid sites. In particular, the Ga- and Zr-A3-SBA-15 materials had the strongest and largest amounts of both types of acid sites, which can be attributed to the higher heteroatom loadings of these two materials. Furthermore, the broad TPD curves observed for Ga- and Zr-A3-SBA-14 are consistent with the pyridine IR results. The A3SBA-15 and Al- and Ti-SBA-15 materials did not exhibit peaks in the Brønsted acid region of the IR spectra because the strengths of these acid sites were likely not significant enough to 
measure. Additionally, the ${ }^{27} \mathrm{Al}$ NMR results indicated the likelihood of more total Lewis acid sites in Al-A3-SBA-15 because of the larger amount of octahedral Al present in the sample. The pyridine IR results suggest that the nature of the synthesis of the heteroatom material, as well as the chemical and physical properties of the heteroatom itself, contributed to the strengths and amounts of the Brønsted and Lewis acid sites present in each material.

\subsection{Catalytic Behavior of Heteroatom Functionalized Materials}

For the model aldol condensation reaction of 4-nitrobenzaldehyde with acetone, each heteroatom-substituted catalyst is observed to be less active than the standard silica material A3SBA-15 (Fig. 10). The initial turnover frequencies (TOF) are reported for all materials in Table

2. This observation is consistent with published reports using a heteroatom-substituted aminosilica, whereby the authors observed lower catalytic rates when using $\mathrm{Al}$ as a heteroatom in the silica matrix $[13,39]$. For the $\mathrm{M}^{3+}$ heteroatoms, each material has a similar catalytic activity (between a factor of $0.6-0.75$ of the catalytic activity of A3-SBA-15). Given the variability of acid strength and total number of acid sites for the heteroatom incorporated silicas, this behavior is surprising, especially considering the high Ga loading for Ga-A3-SBA-15. These similarities could reflect the low heteroatom substitution of the B- and Al-SBA-15 materials, though these results suggest it would be disadvantageous to further increase the $\mathrm{B}$ and $\mathrm{Al}$ heteroatom content. The Ga-A3-SBA-15 material has the highest activity for the aldol condensation of all three $\mathrm{M}^{3+}$ heteroatom materials. While the Ga-substituted silica has the highest heteroatom content of the $\mathrm{M}^{3+}$ materials, it also has the strongest and largest number of Lewis acid sites. The decrease in catalytic activity for the array of $\mathrm{M}^{3+}$ heteroatom materials may be attributed to the increased total number and strength of the acid sites present in the silica 
supports, as a previous report showed that stronger Brønsted acid sites inhibit the aldol condensation [18]. This is likely due to non-productive, strong amine-acid interactions, removing the amine from the pool of sites available to activate the reagents.

The $\mathrm{M}^{4+}$ heteroatom substitutions also lowered the rate of reaction relative to A3-SBA15. This behavior is surprising for Ce because it is known to have more basic character, and the aldol condensation is more active in the presence of weaker acids [86]. The behavior of $\mathrm{Zr}-\mathrm{A} 3$ SBA-15 is expected because the $\mathrm{Zr}$ heteroatoms serve as Lewis acid sites, which bind Lewis bases, and the acid-base interaction would reduce the catalytic activity [53,87,88]. The TPD and pyridine IR results for Zr-A3-SBA-15 indicate it has the largest number of Lewis acid sites (most at $50{ }^{\circ} \mathrm{C}$ ) and the largest number of strong acid sites (most at $200{ }^{\circ} \mathrm{C}$ ) of all the amine-silanol catalysts, which explains why the other Lewis-acidic catalysts such as B-, Al,-, and Ti-A3-SBA15 are more active than Zr-A3-SBA-15 in the aldol condensation. The results for Ga-A3-SBA-15 and $\mathrm{Zr}$-SBA-15 suggest that the physical geometry of the heteroatom in the silica framework that creates the Lewis acid site affects the catalytic activity. As mentioned above, coordinatively unsaturated $\mathrm{Ga}^{3+}$ species create Lewis acid sites in Ga-substituted silica [65] while Zr-O-Si linkages create Lewis acid sites in Zr-substituted silica [69]. These $\mathrm{Zr}-\mathrm{O}-\mathrm{Si}$ linkages distort the silica framework and induce an increased Brønsted acidity in the silanols, which would explain why the larger number of strong Lewis acid sites of Zr-A3-SBA-15 inhibit the aldol condensation more severely compared to Ga-A3-SBA-15, which also has a large number of strong Lewis acid sites. Trukhan et al. synthesized a series of Ti-substituted silicates, including Ti-SBA-15, and concluded via FTIR spectra of adsorbed $\mathrm{CD}_{3} \mathrm{CN}$ that the addition of Ti to the silica materials increased the strength of the surface Brønsted acid sites (titanols), though not as much when compared to Al-doped silica materials [33]. Furthermore, they observed differences 
in acid strength for the materials depending on the nature of the synthetic conditions, the extent of surface hydroxylation, and Ti dispersion in the silica framework [33]. Titanols on the surface of mesoporous silicas provide stronger Brønsted acidity than silanols, which explains the decreased activity of Ti-A3-SBA-15 compared to the A3-SBA-15 for the aldol condensation, though the pyridine IR results for both the A3-SBA-15 and Ti-A3-SBA-15 indicated very weak Brønsted acidity $[48,89]$.

In addition to the effects of the heteroatoms themselves, the optimal alkyl linker length may have changed after heteroatom substitution due to changes in the silica microstructure, despite the large pore volume. For small pores $(2.3 \mathrm{~nm})$, long alkyl linkers resulted in lower rates of reaction for the aldol condensation of 4-nitrobenzaldehyde with acetone at $50{ }^{\circ} \mathrm{C}$ over silica supports [3]. However, the increased number of acid sites and morphologies of the heteroatom materials may alter the required distances of the acid-base cooperative interactions. To examine this possibility, two materials were synthesized with aminomethyl (A1) groups, rather than aminopropyl moieties, tethered to the surface: one was substituted with $\mathrm{Al}\left(\mathrm{M}^{3+}\right)$ and the other was substituted with $\mathrm{Ti}\left(\mathrm{M}^{4+}\right)$. Interestingly, both aminomethyl-functionalized materials exhibited the same behavior as the pure silica material functionalized with aminomethyl groups [19]. The apparent conversion of 4-nitrobenzaldehyde reached $\sim 10 \%$ after $4 \mathrm{~h}$ (Fig. 11), consistent with a quantitative reaction of the aldehyde with the surface amine to produce an imine. In the previously proposed mechanism, the nucleophilic amine attacks the silanolactivated acetone creating an enamine, which is followed by reaction with the acid-activated aldehyde [19]. For the aminomethyl catalysts, cooperative activation of the acetone was hypothesized to be inefficient due to the short linker length, and stoichiometric imine formation was observed, which was suggested to represent an off-cycle adduct that formed because the 
catalyst cannot efficiently activate the acetone and turnover catalytically [19]. Thus, in this work, as well as in the previous study, the amines behaved as if they were isolated from Brønsted acidic silanol species. These results indicate the aminomethyl group provides an amine site that is effectively isolated from acidic surface hydroxyls.

In contrast to the above results, the observed catalytic activities changed significantly for the model nitroaldol condensation reaction and actually increased for all $\mathrm{M}^{3+}$ heteroatom substitutions (Al, Ga, and B) and for the Ti-substituted material (Fig. 12). This increase in catalytic activity could reflect the influence of the Lewis acid sites of the heteroatom materials compared to A3-SBA-15, resulting in more efficient catalytic cooperativity with the proposed [3] two surface acid sites (for the heteroatom materials, the Lewis acid sites may serve the same role as the hydroxyl groups) that are suggested to play a role in the reaction. Another proposed mechanism for the nitroaldol reaction requires only basic catalytic moieites and involves imine formation as an intermediate [90,91]. However, the base-only mechanism is slower than the acidassisted mechanism.

In previous work using heteroatom-free silica materials, the distance between the acid sites and basic amines strongly influenced the observed catalytic activity in the nitroaldol condensations, while it played a more modest role in the aldol condensation. For the aldol condensation on SBA-15 silica with a $6.5 \mathrm{~nm}$ pore diameter, it was shown that the catalytic activity increased as the length of the alkyl linker increased from one carbon $(\mathrm{C} 1)$ to three carbons (C3), but further increasing the linker length to C5 or even C11 did not significantly increase or decrease the activity compared to the C3 linker [3,19]. Conversely, for the nitroaldol condensation on the same series of SBA-15 silica materials with a $6.5 \mathrm{~nm}$ pore diameter, the activity continued to increase as the linker length increased from $\mathrm{C} 1$ to $\mathrm{C} 5$, though a slight 
decrease in activity for $\mathrm{C} 11$ relative to $\mathrm{C} 5$ was observed, most likely because the longer linker could not interact with the silanols as efficiently as the shorter C5 linker [3]. Knowing that the nitroaldol condensation was more sensitive to the alkyl linker length than the aldol condensation and that the proposed nitrolaldol mechanism [3] relies on two acid sites compared to one acid site for the aldol mechanism [19], it is interesting to note that increasing the number of Lewis acid sites available to the amines for cooperative interactions increases the activity of four of the heteroatom-containing materials for the nitroaldol condensation. Thus, the nitroaldol condensation is more sensitive to amine-silanol site pairing and the presence of additional Lewis acid sites, whereas the aldol condensation is less affected by these variables.

However, it should be noted that the increased activity observed in the nitroaldol condensation occurred only for four of the six heteroatom materials evaluated (B-, Al-, Ga-, and Ti-A3-SBA-15) and a dramatic decrease in catalytic activity for Zr-A3-SBA-15 was observed relative to the pure silica case. The B-, Al-, and Ti-A3-SBA-15 materials were the most active catalysts and had smaller amounts of Lewis acid sties. The Ce-A3-SBA-15 material had the least amount of Lewis acid sites and thus behaved nearly identically to the A3-SBA-15 catalyst. The Zr-A3-SBA-15 material had the most Lewis acid sites of the six heteroatom materials and was the least catalytically active, with a rate below that of the heteroatom-free material. The materials with the second largest number of Lewis acid sites, Ga-A3-SBA-15, was found to be slightly more active than the A3-SBA-15 catalyst. These results suggest that adding very small amounts of Lewis acid sites (Ce-A3-SBA-15) had a negligible effect on catalytic activity for the nitroaldol condensation, while adding modest amounts of Lewis acid sites (B-, Al-, and Ti-SBA-15) increased the catalytic activity. Continuing to increase the number of Lewis acid sites (Ga-A3SBA-15) decreased the activity somewhat, though was still beneficial compared to A3-SBA-15. 
Inclusion of too much Lewis acidity (Zr-A3-SBA-15) was detrimental to the activity of the heteroatom material. At this stage, the observed trends in catalytic activity for all the heteroatom materials are tentatively attributed to the total number of Lewis acid sites, rather than the strength of the acid sites. With the varying amounts of heteroatoms in each of the materials, definitive conclusions cannot be drawn about the strengths of the Lewis acid sites based on the type of heteroatom present. However, incorporating even modest amounts of Lewis acid sites relative to the heteroatom-free A3-SBA-15 material appears to have a significant effect on the cooperative catalytic behavior of these materials, so at this stage, the trends in catalytic activity cannot be definitively ascribed to nature or the strength of the sites, and a correlation with total number of sites is most appropriate. Thus, just as there was an optimal amine linker length for the nitroaldol condensation in the previous work [3,19], there appears to be an optimal amount of Lewis acidity for increasing the reaction rate in the nitroaldol reaction.

The effect of amine linker length was also probed for selected heteroatom-containing materials. Fig. 13 shows the results of the nitroaldol condensation for Al- and Ti-substituted materials functionalized with aminopentyl (A5) groups instead of aminopropyl species. The initial rate of reaction for the longer alkyl amine in the nitroaldol condensation was identical to the rate of reaction for the aminopropyl-functionalized heteroatom materials, though the reaction yields were lower at longer reaction times when using the longer linkers. In the case of the nitroaldol condensation, the incorporation of $\mathrm{Al}$ or $\mathrm{Ti}$ heteroatoms in the material provided an similar increase in catalytic activity as increasing the length of the alkyl linker from C3 to C5 on pure silica support materials with a large $(6.5 \mathrm{~nm})$ pore diameter, as discussed previously [3]. However, the data in Fig. 13 demonstrate that the rate is not further increased over the $\mathrm{Ti}$ and $\mathrm{Al}$ 
heteroatom containing materials by using the C5 linker, and thus the rate enhancements associated with longer linkers and heteroatoms do not appear to be additive.

Table 4 shows the reaction schemes, products, and selectivity after $4 \mathrm{~h}$ toward each product for the six heteroatom materials and A3-SBA-15 for the aldol and nitroaldol condensations. For the aldol condensation, the standard A3-SBA-15 catalyst favored formation of the aldol product $(\mathbf{1}, 77 \%$ selectivity) compared to the unsaturated dehydration product (2, $23 \%$ selectivity). This ratio of 3:1 in favor of the aldol product is in agreement with Zeidan and Davis's original report for an aminosilica catalyst with no heteroatom content [11]. The heteroatom materials with fewer total acid sites (e.g. B-, Al-, Ti-, and Ce-A3-SBA-15) were selective toward the aldol product while the heteroatom materials with more total acid sites (e.g. Ga- and Zr-A3-SBA-15) were selective toward the unsaturated dehydration product. Zeidan and Davis also observed a higher preference for the aldol product when using weaker organic acids such as phosphoric and carboxylic acids compared to a stronger sulfonic acid [12]. While incorporating inorganic heteroatoms into the silica framework decreased the activity for the aldol condensation, doing so also increased the selectivity toward the unsaturated product, which could prove useful in future applications if that product is desired.

The nitroaldol condensation yielded three different products: the $\beta$-nitroalcohol (3), the 1,3-dinitroalkane (4), and the $\beta$-nitrostyrene (5). The 1,3-dinitroalkane is formed via a Michael addition of the excess nitromethane to the $\beta$-nitrostyrene $[43,92,93]$. The standard A3-SBA-15 material exhibited $77 \%$ selectivity toward the $\beta$-nitrostyrene and $23 \%$ selectivity toward the 1,3 dinitroalkane. No $\beta$-nitroalcohol was present in the ${ }^{1} \mathrm{H}$ NMR spectrum. The results are consistent with literature reports where primary amines on mesoporous silica materials favored the formation of $\beta$-nitrostyrene with yields similar to those observed here while secondary and 
tertiary amines favored the formation of the $\beta$-nitroalcohol [94,95]. The four most active heteroatom materials for the nitroaldol condensation (B-, Al-, Ga-, and Ti- SBA-15) all exhibited the same selectivity toward the $\beta$-nitrostyrene and the 1,3-dinitroalkane as the A3-SBA-15 material, though Ti-A3-SBA-15 formed a trace amount of the $\beta$-nitroalcohol (less than $1 \%$ selectivity). Conversely, the two least active heteroatom materials for the nitroaldol condensation, Zr- and Ce-A3-SBA-15, exhibited appreciable selectivity (32\% and 35\%, respectively) toward the $\beta$-nitroalcohol. These results suggest that primary amines could be used with $\mathrm{Zr}$ - and $\mathrm{Ce}$-substituted silicas to create catalysts that favor the formation of $\beta$-nitroalcohols if the amounts of heteroatoms can be tuned to increase the catalytic activity compared to the results obtained here without sacrificing selectivity. However, increasing the amount of Lewis acid sites did not appear to affect the selectivity of the nitroaldol condensation, given that GaA3-SBA-15 had the same selectivity as A3-SBA-15, which does not have Lewis acid sites. Additionally, the large difference in total acid sites between Zr-A3-SBA-15 and Ce-A3-SBA-15 further supports the notion that the number of acid sites did not affect the selectivity. It is more likely that the electronic character of the heteroatoms controlled the selectivity. None of the $\mathrm{M}^{3+}$ elements ( $\mathrm{B}, \mathrm{Al}, \mathrm{Ga})$ formed the $\beta$-nitroalcohol, but all three $\mathrm{M}^{4+}$ elements (Ti, $\left.\mathrm{Zr}, \mathrm{Ce}\right)$ did, though Ti-A3-SBA-15 formed the $\beta$-nitroalcohol in a trace amount. Catalysts containing Brønsted acid sites are known to be more selective toward the dehydration of secondary alcohols while catalysts containing Lewis acid sites are more selective toward dehydration of primary alcohols [96,97]. The large number of Brønsted acid sites for the Zr-A3-SBA-15 material seems to contradict this notion because this catalyst formed the $\beta$-nitroalcohol, a secondary alcohol, with moderate selectivity (32\%). However, the varying amounts of Brønsted acid sites among the heteroatom materials used here make it difficult to determine the cause of the alcohol 
dehydration. At this stage, the exact reason for the formation of $\beta$-nitroalcohol of the $\mathrm{M}^{4+}$ catalysts remains unclear, but future studies of $\mathrm{M}^{3+}$ and $\mathrm{M}^{4+}$ heteroatom materials containing different amounts of heteroatoms could prove useful in elucidating the switch in selectivity.

The combined results of the aldol and nitroaldol condensations on the heteroatom materials provide strong evidence that each reaction proceeds via significantly different pathways. Our previous work, in conjunction with homogeneous mechanisms for the two reactions reported in the literature, suggest the aldol condensation proceeds with two important steps facilitated by a hydrogen bonding or proton exchange interaction $[98,99]$. These steps are sequential with one step being the initial dual activation of the ketone (acetone) and the second step being a transition-state stabilized acid-base interaction. The same hydroxyl can be used for both stabilizations because the aforementioned acid-base interactions are sequential. The reaction data shown here for the nitroaldol condensation is consistent with the previous hypothesis [3] that multiple hydroxyls (or Lewis acid sites) are involved in the reaction, suggesting this mechanism involves two acid sites simultaneously activating the aldehyde and the nitro group of nitromethane in a concerted fashion [3]. This difference between the two mechanisms may also be responsible for the differences in catalytic activity for the two reactions when substituting heteroatoms into the surface of the material, though at this stage, this remains speculative. Regardless, the nitroaldol condensation is clearly more sensitive to acid-base pairing than the aldol condensation.

\section{Conclusions}

A series of amine-functionalized silica bifunctional catalysts with various heteroatom substitutions was prepared to probe the effects of the substitutions on the cooperative catalytic 
behavior of these modified materials in the aldol and nitroaldol condensations. Ammonia TPD of the heteroatom materials demonstrated the increased total number of acid sties of the heteroatom substituted materials in all cases. It was determined that the increased number and strength of the Lewis acid sites of each heteroatom material decreased the catalytic activity compared to the standard aminosilica catalyst A3-SBA-15 for the aldol condensation of 4-nitrobenzaldehyde with acetone, which is inhibited by stronger acids. For the nitroaldol condensation of 4nitrobenzaldehyde with nitromethane, the increased number of Lewis acid sites of four heteroatom materials (B-, Al-, Ga-, and Ti-A3-SBA-15) increased the catalytic activity compared to heteroatom-free A3-SBA-15. The catalytic activity in the nitroaldol condensation for Ti and Al containing aminopentyl-functionalized materials was not enhanced compared to the aminopropyl case, showing that rate enhancements observed over heteroatom-free silica catalysts with longer alkyl linkers and rate enhancements associated with moderate Lewis acidity associated with these two heteroatoms were not additive. These results further support the notion that the aldol and nitroaldol reactions proceed through different mechanisms.

\section{Acknowledgments}

This work was supported by the Department of Energy Office of Basic Energy Sciences through Catalysis Contract No. DEFG02-03ER15459. We thank Dr. Johannes Leisen for conducting solid-state NMR experiments, Mr. Kiwon Eum for collecting SEM images, Mr. Guo Shiou Foo for his help in performing pyridine IR experiments, and Ms. Caroline Hoyt for her help with ${ }^{1} \mathrm{H}$ NMR experiments.

\section{Appendix A. Supporting Information}


Supporting information associated with this article can be found in the online version. The supporting information includes the synthesis of SBA-15 and the six heteroatom materials as well as the SEM images and pyridine IR spectra of all aminosilica materials.

\section{References}

[1] E.L. Margelefsky, R.K. Zeidan, M.E. Davis, Chem. Soc. Rev. 37 (2008) 1118-1126.

[2] S. Shylesh, W.R. Thiel, ChemCatChem 3 (2011) 278-287.

[3] N.A. Brunelli, C.W. Jones, J. Catal. 308 (2013) 60-72.

[4] P.I. Dalko, L. Moisan, Angew. Chem. Int. Ed. 43 (2004) 5138-5175.

[5] D.W.C. MacMillan, Nature 455 (2008) 304-308.

[6] U. Scheffler, R. Mahrwald, Chem. Eur. J. 19 (2013) 14346-14396.

[7] W. Notz, F. Tanaka, C.F. Barbas, Acc. Chem. Res. 37 (2004) 580-591.

[8] C. Grondal, M. Jeanty, D. Enders, Nat. Chem. 2 (2010) 167-178.

[9] C.K.W. Kwong, R. Huang, M. Zhang, M. Shi, P.H. Toy, Chem. Eur. J. 13 (2007) 23692376.

[10] Y. Han, H. Huang, H. Zhang, Y. Liu, X. Han, R. Liu, H. Li, Z. Kang, ACS Catal. 4 (2014) 781-787.

[11] R.K. Zeidan, S.J. Hwang, M.E. Davis, Angew. Chem. Int. Ed. 45 (2006) 6332-6335.

[12] R.K. Zeidan, M.E. Davis, J. Catal. 247 (2007) 379-382.

[13] S. Shylesh, A. Wagener, A. Seifert, S. Ernst, W.R. Thiel, ChemCatChem 2 (2010) 12311234.

[14] E. Gianotti, U. Diaz, A. Velty, A. Corma, Catal. Sci. Technol. 3 (2013) 2677-2688.

[15] U. Díaz, D. Brunel, A. Corma, Chem. Soc. Rev. 42 (2013) 4083-4097.

[16] J.D. Bass, A. Solovyov, A.J. Pascall, A. Katz, J. Am. Chem. Soc. 128 (2006) 3737-3747. 
[17] S.L. Hruby, B.H. Shanks, J. Catal. 263 (2009) 181-188.

[18] N.A. Brunelli, K. Venkatasubbaiah, C.W. Jones, Chem. Mater. 24 (2012) 2433-2442.

[19] N.A. Brunelli, S.A. Didas, K. Venkatasubbaiah, C.W. Jones, J. Am. Chem. Soc. 134 (2012) 13950-13953.

[20] J. Lauwaert, E. De Canck, D. Esquivel, J.W. Thybaut, P. Van Der Voort, G.B. Marin, ChemCatChem 6 (2013) 255-264.

[21] H. Yuan, W.J. Yoo, H. Miyamura, S.S. Kobayashi, J. Am. Chem. Soc. 134 (2012) 1397013973.

[22] M.W. McKittrick, C.W. Jones, Chem. Mater. 15 (2003) 1132-1139.

[23] M.W. McKittrick, C.W. Jones, J. Am. Chem. Soc. 126 (2004) 3052-3053.

[24] M.W. McKittrick, C.W. Jones, J. Catal. 227 (2004) 186-201.

[25] L.T. Zhuravlev, Colloids Surfaces A Physicochem. Eng. Asp. 173 (2000) 1-38.

[26] M. Ide, M. El-Roz, E. De Canck, A. Vicente, T. Planckaert, T. Bogaerts, I. Van Driessche, F. Lynen, V. Van Speybroeck, F. Thybault-Starzyk, P. Van Der Voort, Phys. Chem. Chem. Phys. 15 (2013) 642-650.

[27] J.D. Bass, A. Katz, Chem. Mater. (2006) 1611-1620.

[28] Y. Kubota, H. Yamaguchi, T. Yamada, S. Inagaki, Y. Sugi, T. Tatsumi, Top. Catal. 53 (2010) 492-499.

[29] Y. Kubota, K. Goto, S. Miyata, Y. Goto, Y. Fukushima, Y. Sugi, Chem. Lett. 32 (2003) 234-235.

[30] J.D. Bass, S.L. Anderson, A. Katz, Angew. Chem. Int. Ed. 115 (2003) 5377-5380.

[31] J.D. Bass, A. Katz, Chem. Mater. 15 (2003) 2757-2763.

[32] K. Kandel, S.M. Althaus, C. Peeraphatdit, T. Kobayashi, B.G. Trewyn, M. Pruski, I.I. Slowing, ACS Catal. 3 (2013) 265-271.

[33] N.N. Trukhan, A.A. Panchenko, E. Roduner, M.S. Mel'gunov, O.A. Kholdeeva, J. Mrowiec-Białoń, A.B. Jarzebski, Langmuir 21 (2005) 10545-10554.

[34] D.J. Jones, J. Jiménez-Jiménez, A. Jiménez-López, P. Maireles-Torres, P. Olivera-Pastor, E. Rodriguez-Castellón, J. Rozière, Chem. Commun. (1997) 431-432. 
[35] E. Rodríguez-Castellón, A. Jiménez-López, P. Maireles-Torres, D.. Jones, J. Rozière, M. Trombetta, G. Busca, M. Lenarda, L. Storaro, J. Solid State Chem. 175 (2003) 159-169.

[36] S. Imamura, T. Nakai, H. Kanai, T. Ito, J. Chem. Soc. Faraday Trans. 91 (1995) 12611266.

[37] Y. Li, W. Zhang, L. Zhang, Q. Yang, Z. Wei, Z. Feng, C. Li, J. Phys. Chem. B 108 (2004) 9739-9744.

[38] F. Shang, H. Liu, J. Sun, B. Liu, C. Wang, J. Guan, Q. Kan, Catal. Commun. 12 (2011) 739-743.

[39] C. Wang, F. Shang, X. Yu, J. Guan, Q. Kan, Appl. Surf. Sci. 258 (2012) 6846-6852.

[40] K. Motokura, M. Tada, Y. Iwasawa, J. Am. Chem. Soc. 129 (2007) 9540-9541.

[41] K. Motokura, M. Tomita, M. Tada, Y. Iwasawa, Chem. Eur. J. 14 (2008) 4017-4027.

[42] K. Motokura, S. Tanaka, M. Tada, Y. Iwasawa, Chem. Eur. J. 15 (2009) 10871-10879.

[43] K. Motokura, M. Tada, Y. Iwasawa, Angew. Chem. Int. Ed. 47 (2008) 9230-9235.

[44] K. Motokura, M. Tada, Y. Iwasawa, J. Am. Chem. Soc. 131 (2009) 7944-7945.

[45] K. Motokura, M. Tomita, M. Tada, Y. Iwasawa, Top. Catal. 52 (2009) 579-585.

[46] M. Olejniczak, M. Ziolek, Microporous Mesoporous Mater. 196 (2014) 243-253.

[47] D. Blasco-Jiménez, I. Sobczak, M. Ziolek, A.J. López-Peinado, R.M. Martín-Aranda, Catal. Today 152 (2010) 119-125.

[48] D.G. Hanna, S. Shylesh, Y.-P. Li, S. Krishna, M. Head-Gordon, A.T. Bell, ACS Catal. 4 (2014) 2908-2916.

[49] W.H. Zhang, J. Lu, B. Han, M. Li, J. Xiu, P. Ying, C. Li, Chem. Mater. 14 (2002) 34133421.

[50] A. Vinu, V. Murugesan, W. Böhlmann, M. Hartmann, J. Phys. Chem. B 108 (2004) 11496-11505.

[51] Y. Kuwahara, D.Y. Kang, J.R. Copeland, P. Bollini, C. Sievers, T. Kamegawa, H. Yamashita, C.W. Jones, Chem. Eur. J. 18 (2012) 16649-16664.

[52] S.Y. Chen, L.Y. Jang, S. Cheng, Chem. Mater. 16 (2004) 4174-4180.

[53] S.Y. Chen, J.F. Lee, S. Cheng, J. Catal. 270 (2010) 196-205. 
[54] M.D. Kadgaonkar, S.C. Laha, R.K. Pandey, P. Kumar, S.P. Mirajkar, R. Kumar, Catal. Today 97 (2004) 225-231.

[55] M.N. Timofeeva, S.H. Jhung, Y.K. Hwang, D.K. Kim, V.N. Panchenko, M.S. Melgunov, Y.A. Chesalov, J.S. Chang, Appl. Catal. A Gen. 317 (2007) 1-10.

[56] W.W. Lukens, P. Schmidt-Winkel, D. Zhao, J. Feng, G.D. Stucky, Langmuir 15 (1999) 5403-5409.

[57] S. Khabtou, T. Chevreau, J.C. Lavalley, Microporous Mater. 3 (1994) 133-148.

[58] E. Parry, J. Catal. 2 (1963) 371-379.

[59] M.K. Kidder, P.F. Britt, Z. Zhang, S. Dai, E.W. Hagaman, A.L. Chaffee, A.C. Buchanan, J. Am. Chem. Soc. 127 (2005) 6353-6360.

[60] M.K. Kidder, A.C. Buchanan, J. Phys. Chem. C 112 (2008) 3027-3031.

[61] I.T. Ghampson, C. Newman, L. Kong, E. Pier, K.D. Hurley, R.A. Pollock, B.R. Walsh, B. Goundie, J. Wright, M.C. Wheeler, R.W. Meulenberg, W.J. DeSisto, B.G. Frederick, R.N. Austin, Appl. Catal. A Gen. 388 (2010) 57-67.

[62] K. Kandel, S.M. Althaus, C. Peeraphatdit, T. Kobayashi, B.G. Trewyn, M. Pruski, I.I. Slowing, J. Catal. 291 (2012) 63-68.

[63] L. Zhao, Y. Li, P. Yu, X. Han, J. He, ACS Catal. 2 (2012) 1118-1126.

[64] G. Connell, J.A. Dumesic, J. Catal. 298 (1987) 285-298.

[65] G. Turnes Palomino, J. José Cuart Pascual, M. Rodríguez Delgado, J. Bernardo Parra, C. Otero Areán, Mater. Chem. Phys. 85 (2004) 145-150.

[66] G. Muthu Kumaran, S. Garg, K. Soni, M. Kumar, J.K. Gupta, L.D. Sharma, K.S. Rama Rao, G. Murali Dhar, Microporous Mesoporous Mater. 114 (2008) 103-109.

[67] I. Eswaramoorthi, A.K. Dalai, Microporous Mesoporous Mater. 93 (2006) 1-11.

[68] P.D. Young, J.M. Notestein, ChemSusChem 4 (2011) 1671-1678.

[69] J.A. Anderson, C. Fergusson, I. Rodríguez-Ramos, A. Guererro-Ruiz, J. Catal. 192 (2000) 344-354.

[70] Z. Liu, J. Tabora, R.J. Davis, J. Catal. 149 (1994) 117-126.

[71] T. Kataoka, J.A. Dumesic, J. Catal. 112 (1988) 66-79. 
[72] S. Hu, R.J. Willey, B. Notari, J. Catal. 220 (2003) 240-248.

[73] C. Fild, D.F. Shantz, R.F. Lobo, H. Koller, Phys. Chem. Chem. Phys. 2 (2000) 30913098 .

[74] H. Timken, E. Oldfield, J. Am. Chem. Soc. 109 (1987) 7669-7673.

[75] C. Bayense, A. Kentgens, J. Phys. Chem. 96 (1992) 775-782.

[76] K. Okumura, K. Nishigaki, M. Niwa, Microporous Mesoporous Mater. $44-45$ (2001) 509516.

[77] D. Massiot, T. Vosegaard, N. Magneron, D. Trumeau, V. Montouillout, P. Berthet, T. Loiseau, B. Bujoli, Solid State Nucl. Magn. Reson. 15 (1999) 159-169.

[78] J.T. Ash, P.J. Grandinetti, Magn. Reson. Chem. 44 (2006) 823-831.

[79] L.A. O’Dell, S.L.P. Savin, A. V. Chadwick, M.E. Smith, Appl. Magn. Reson. 32 (2007) 527-546.

[80] E. Sacaliuc, A.M. Beale, B.M. Weckhuysen, T.A. Nijhuis, J. Catal. 248 (2007) 235-248.

[81] G. Li, X.S. Zhao, Ind. Eng. Chem. Res. 45 (2006) 3569-3573.

[82] L.F. Chen, J.A. Wang, L.E. Noreña, J. Aguilar, J. Navarrete, P. Salas, J.A. Montoya, P. Del Ángel, J. Solid State Chem. 180 (2007) 2958-2972.

[83] S.-C. Moon, M. Fujino, H. Yamashita, M. Anpo, J. Phys. Chem. B 101 (1997) 369-373.

[84] X. Gao, J.L.G. Fierro, I.E. Wachs, Langmuir 15 (1999) 3169-3178.

[85] M.S. Morey, G.D. Stucky, S. Schwarz, M. Fröba, J. Phys. Chem. B 103 (1999) 20372041.

[86] C. Ji, Y. Peng, C. Huang, N. Wang, Y. Jiang, Synlett 2005 (2005) 986-990.

[87] A. Ramanathan, M.C. Castro Villalobos, C. Kwakernaak, S. Telalovic, U. Hanefeld, Chem. Eur. J. 14 (2008) 961-972.

[88] M.S. Wong, H.C. Huang, J.Y. Ying, Chem. Mater. 14 (2002) 1961-1973.

[89] H. Han, H. Frei, J. Phys. Chem. C 112 (2008) 8391-8399.

[90] G. Demicheli, R. Maggi, A. Mazzacani, P. Righi, C. Organica, A. Mangini, Tetrahedron Lett. 42 (2001) 2401-2403. 
[91] D. Zorn, V.S.Y. Lin, M. Pruski, M.S. Gordon, J. Phys. Chem. A 112 (2008) 1063510649.

[92] R. Ballini, G. Bosica, D. Fiorini, A. Palmieri, Synthesis (Stuttg). 2 (2004) 1938-1940.

[93] T. Hara, S. Kanai, K. Mori, T. Mizugaki, K. Ebitani, K. Jitsukawa, K. Kaneda, J. Org. Chem. 71 (2006) 7455-7462.

[94] A. Anan, R. Vathyam, K.K. Sharma, T. Asefa, Catal. Letters 126 (2008) 142-148.

[95] Q. Wang, D.F. Shantz, J. Catal. 271 (2010) 170-177.

[96] G.S. Foo, D. Wei, D.S. Sholl, C. Sievers, ACS Catal. 4 (2014) 3180-3192.

[97] Z. Wang, L. Wang, Y. Jiang, M. Hunger, J. Huang, ACS Catal. 4 (2014) 1144-1147.

[98] B. List, R.A. Lerner, C.F. Barbas, J. Am. Chem. Soc. 122 (2000) 2395-2396.

[99] S. Bahmanyar, K.N. Houk, J. Am. Chem. Soc. 123 (2001) 11273-11283. 
Table 1. Physical parameters of the amine-functionalized silica bifunctional catalysts.

\begin{tabular}{cccccc}
\hline & Surface Area & Total PoreVolume & Pore Diameter & Particle Size & Amine Loading \\
Material & $\left(\mathrm{m}^{2} / \mathrm{g}\right)$ & $\left(\mathrm{cm}^{3} / \mathrm{g}\right)$ & $(\mathrm{nm})$ & $(\mu \mathrm{m})$ & $(\mathrm{mmol} / \mathrm{g}$ Silica $)$ \\
\hline A3-SBA-15 & 930 & 1.34 & 6.9 & 0.2 & 0.36 \\
B-A3-SBA-15 & 918 & 1.14 & 7.0 & 0.7 & 0.48 \\
Al-A3-SBA-15 & 1001 & 0.94 & 8.2 & 2.2 & 0.42 \\
Ga-A3-SBA-15 & 734 & 1.30 & 8.0 & 0.8 & 0.56 \\
Ti-A3-SBA-15 & 725 & 1.30 & & & \\
Zr-A3-SBA-15 & 851 & 1.02 & 9.9 & 0.8 & 0.44 \\
Ce-A3-SBA-15 & 992 & 1.34 & 8.1 & 0.8 & 0.54 \\
\hline
\end{tabular}


Table 2. Initial TOFs and heteroatom content of the six heteroatom materials and aminopropylfunctionalized SBA-15 for the nitroaldol and aldol condensations. The relative rate is the ratio of the TOF of the heteroatom material to the A3-SBA-15 material.

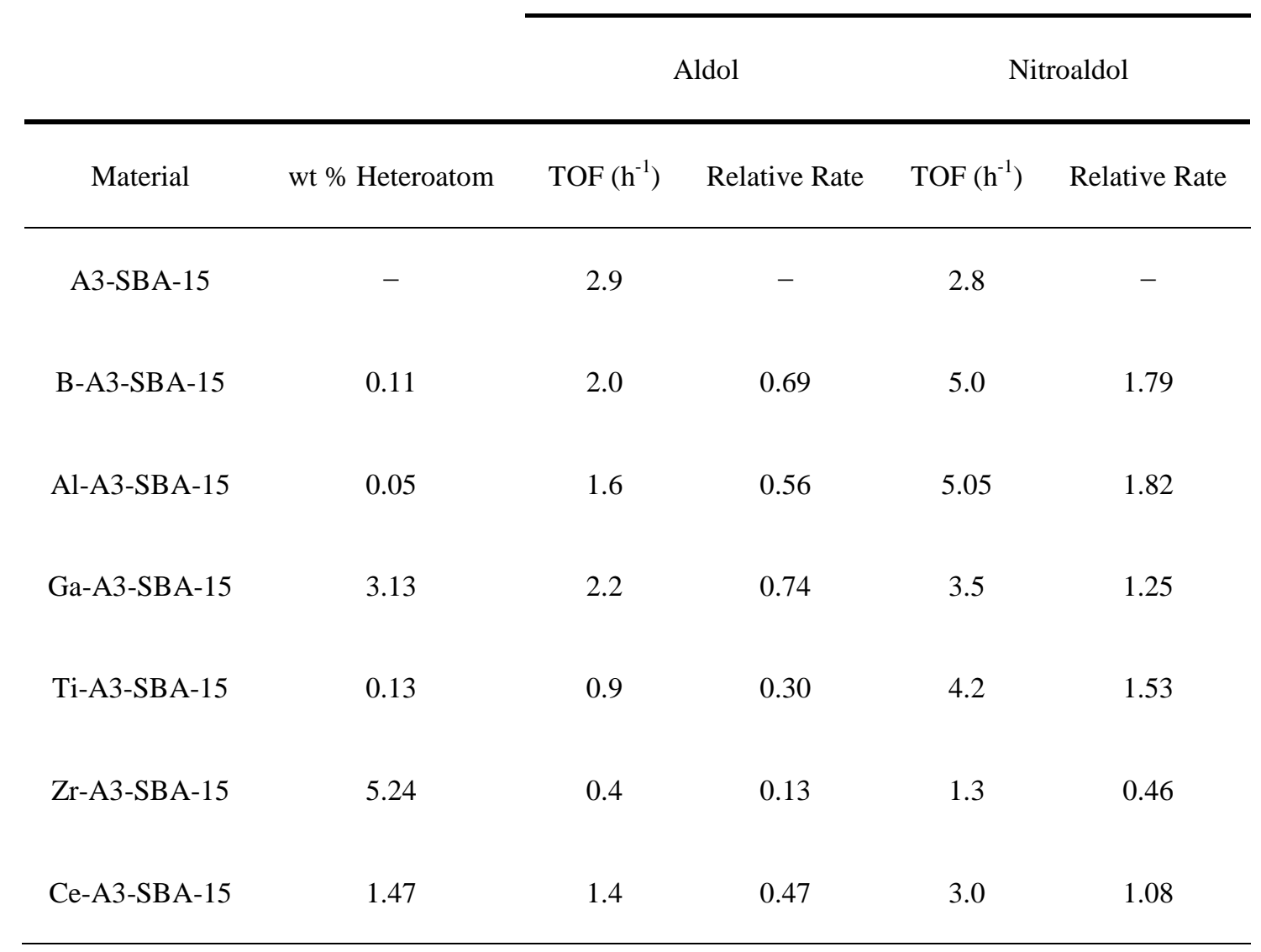


Table 3. Total amounts of Brønsted and Lewis acid sites for the six heteroatom materials and the standard A3-SBA-15 material as determined via pyridine IR experiments.

\begin{tabular}{|c|c|c|c|c|c|c|}
\hline & \multicolumn{3}{|c|}{ Brønsted Acid Sites ( $\mu \mathrm{mol} / \mathrm{g}$ Silica) } & \multicolumn{3}{|c|}{ Lewis Acid Sites ( $\mu \mathrm{mol} / \mathrm{g}$ Silica) } \\
\hline Material & $50{ }^{\circ} \mathrm{C}$ & $100{ }^{\circ} \mathrm{C}$ & $200{ }^{\circ} \mathrm{C}$ & $50^{\circ} \mathrm{C}$ & $100{ }^{\circ} \mathrm{C}$ & $200^{\circ} \mathrm{C}$ \\
\hline A3-SBA-15 & 0 & 0 & 0 & 0 & 0 & 0 \\
\hline B-A3-SBA-15 & 2 & 2 & 0 & 55 & 30 & 12 \\
\hline Al-A3-SBA-15 & 0 & 0 & 0 & 18 & 8 & 5 \\
\hline Ga-A3-SBA-15 & 23 & 11 & 5 & 85 & 58 & 38 \\
\hline Ti-A3-SBA-15 & 0 & 0 & 0 & 39 & 16 & 6 \\
\hline Zr-A3-SBA-15 & 25 & 22 & 13 & 182 & 134 & 89 \\
\hline Ce-A3-SBA-15 & 3 & 1 & 0 & 10 & 4 & 4 \\
\hline
\end{tabular}


Table 4. Reaction schemes and product selectivity for the aldol and nitroaldol condensations on A3-SBA-15 and the six heteroatom materials after $4 \mathrm{~h}$. Product distributions were determined using ${ }^{1} \mathrm{H}$ NMR spectroscopy. Water is lost upon formation of $\mathbf{2}$ and $\mathbf{5}$ (4 is formed from $\mathbf{5}$ ).
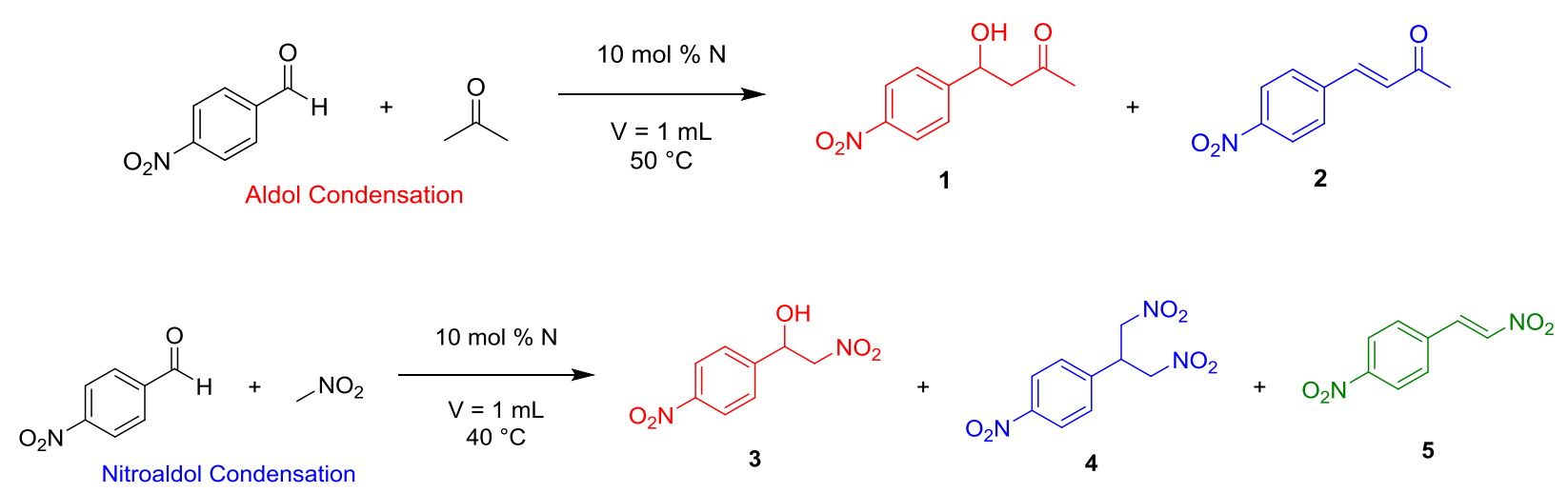

Aldol

Nitroaldol

\begin{tabular}{|c|c|c|c|c|c|}
\hline Material & $1(\%)$ & $2(\%)$ & $3(\%)$ & $4(\%)$ & $5(\%)$ \\
\hline A3-SBA-15 & 77 & 23 & 0 & 23 & 77 \\
\hline B-A3-SBA-15 & 77 & 23 & 0 & 23 & 77 \\
\hline Al-A3-SBA-15 & 65 & 35 & 0 & 24 & 76 \\
\hline Ga-A3-SBA-15 & 44 & 56 & 0 & 22 & 78 \\
\hline Ti-A3-SBA-15 & 74 & 26 & $<1$ & 22 & 78 \\
\hline Zr-A3-SBA-15 & 35 & 65 & 35 & 15 & 50 \\
\hline Ce-A3-SBA-15 & 58 & 42 & 32 & 17 & 51 \\
\hline
\end{tabular}




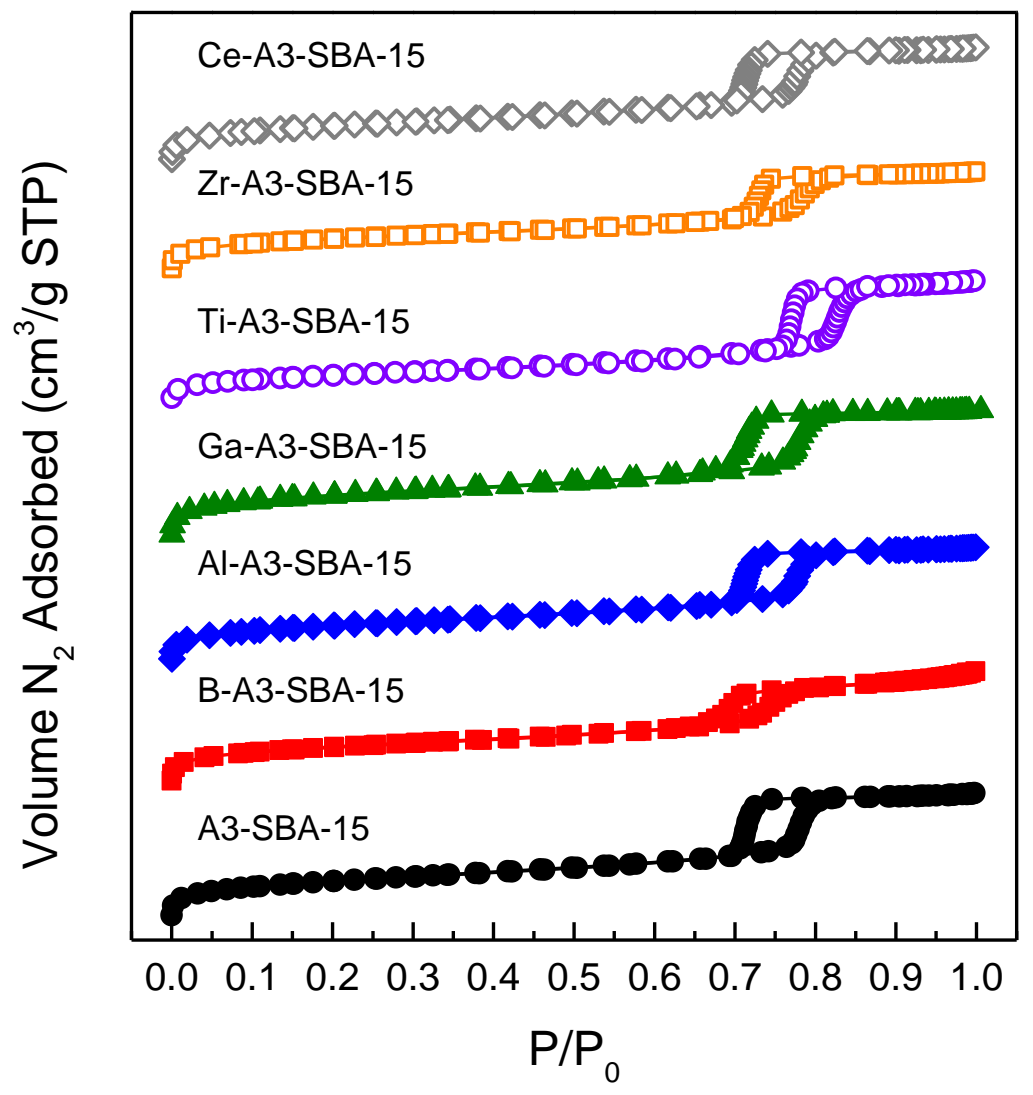

Fig. 1. Nitrogen physisorption isotherms for A3-SBA-15 and the heteroatom-substituted SBA-15 materials. 


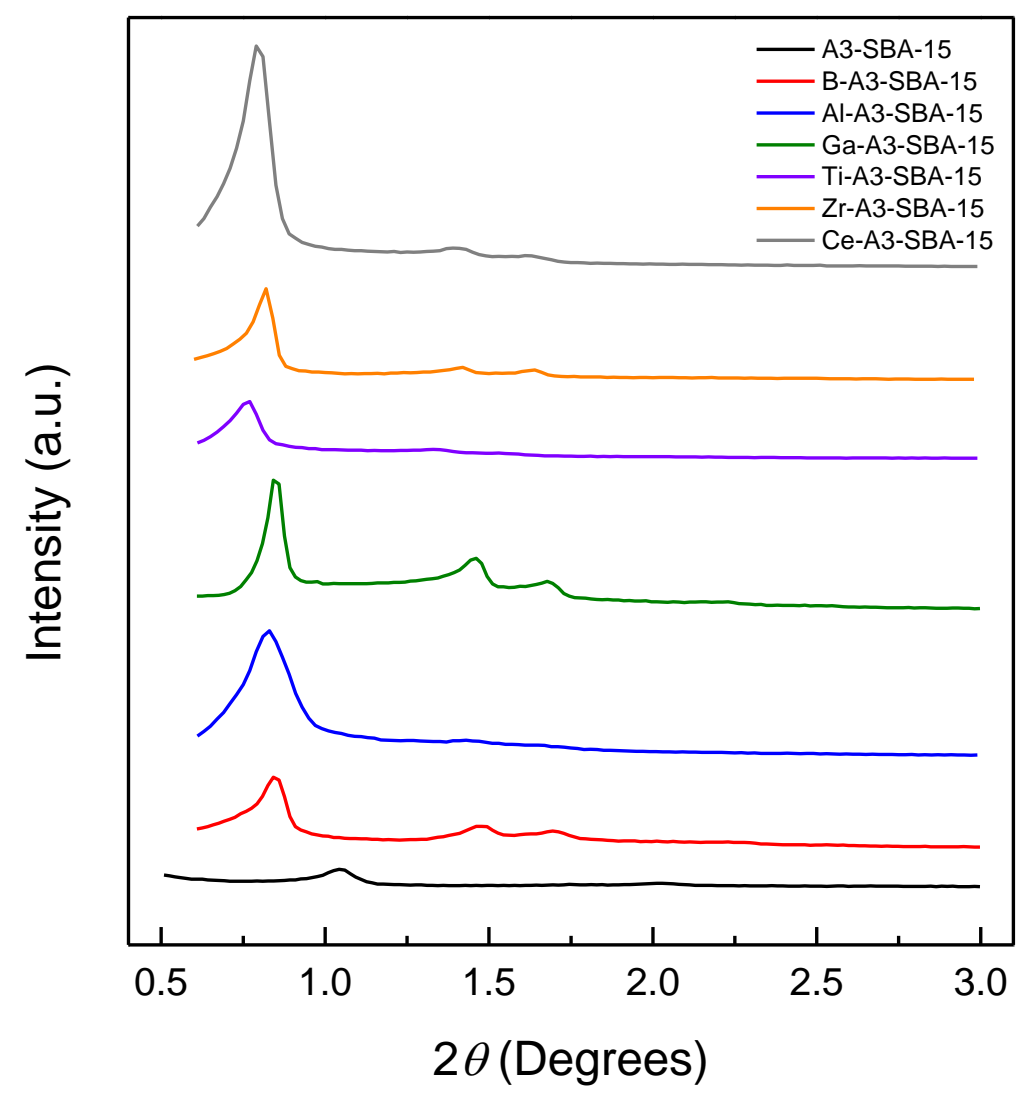

Fig. 2. XRD patterns of A3-SBA-15 and the six heteroatom-functionalized materials. 


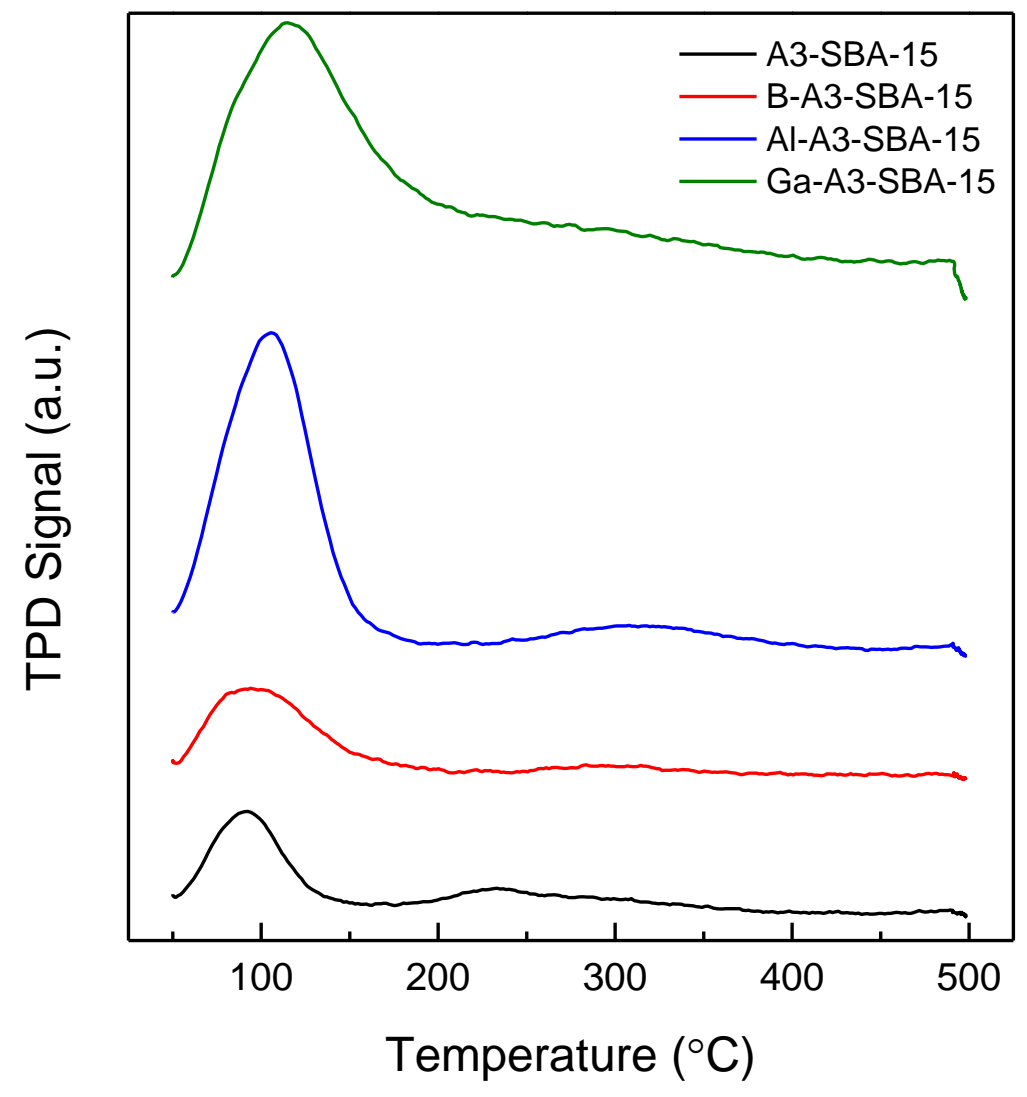

Fig. 3. TPD profiles of the $\mathrm{M}^{3+}$ functionalized heteroatom-containing materials. A3-SBA-15 is shown for comparison. 


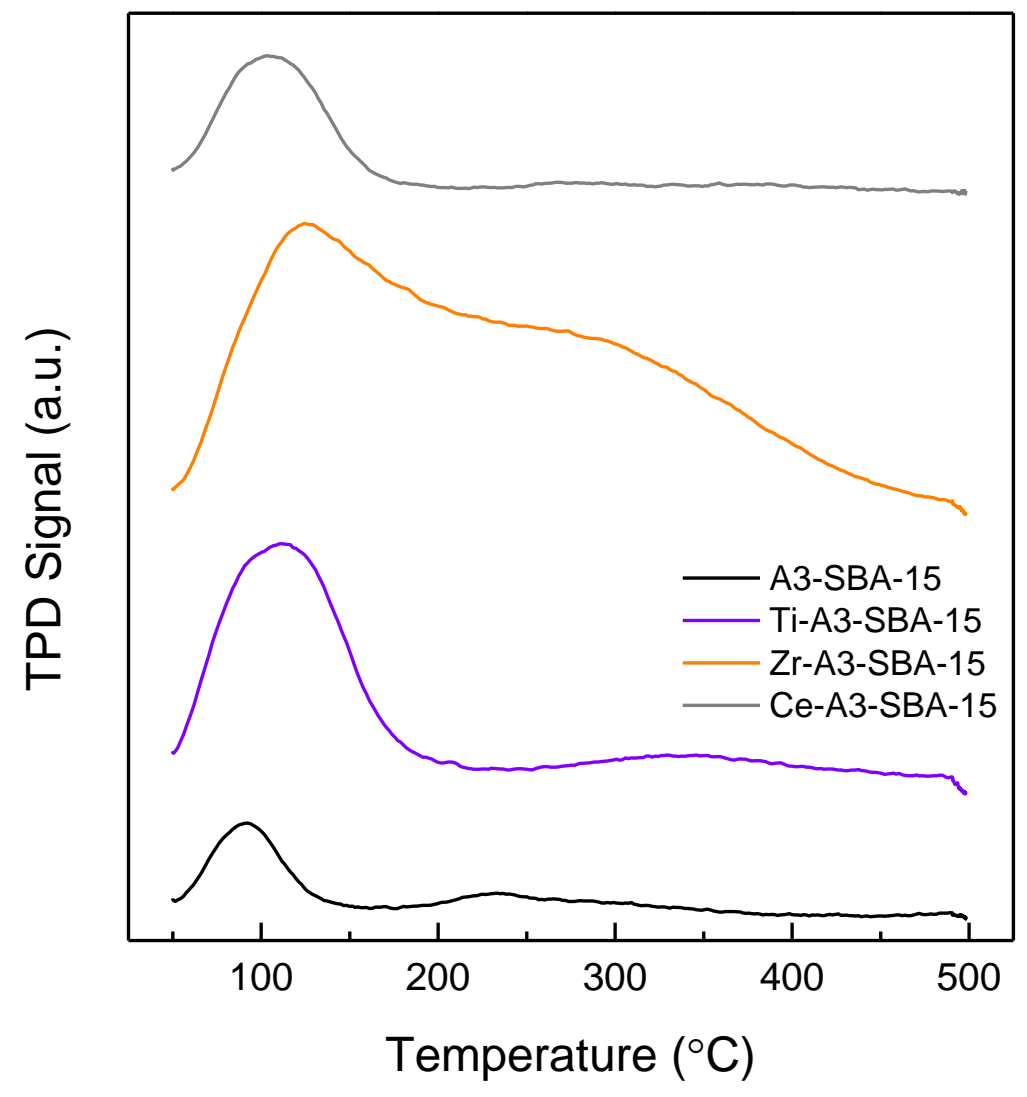

Fig. 4. TPD profiles of the $\mathrm{M}^{4+}$ heteroatom-containing materials. A3-SBA-15 is shown for comparison. 


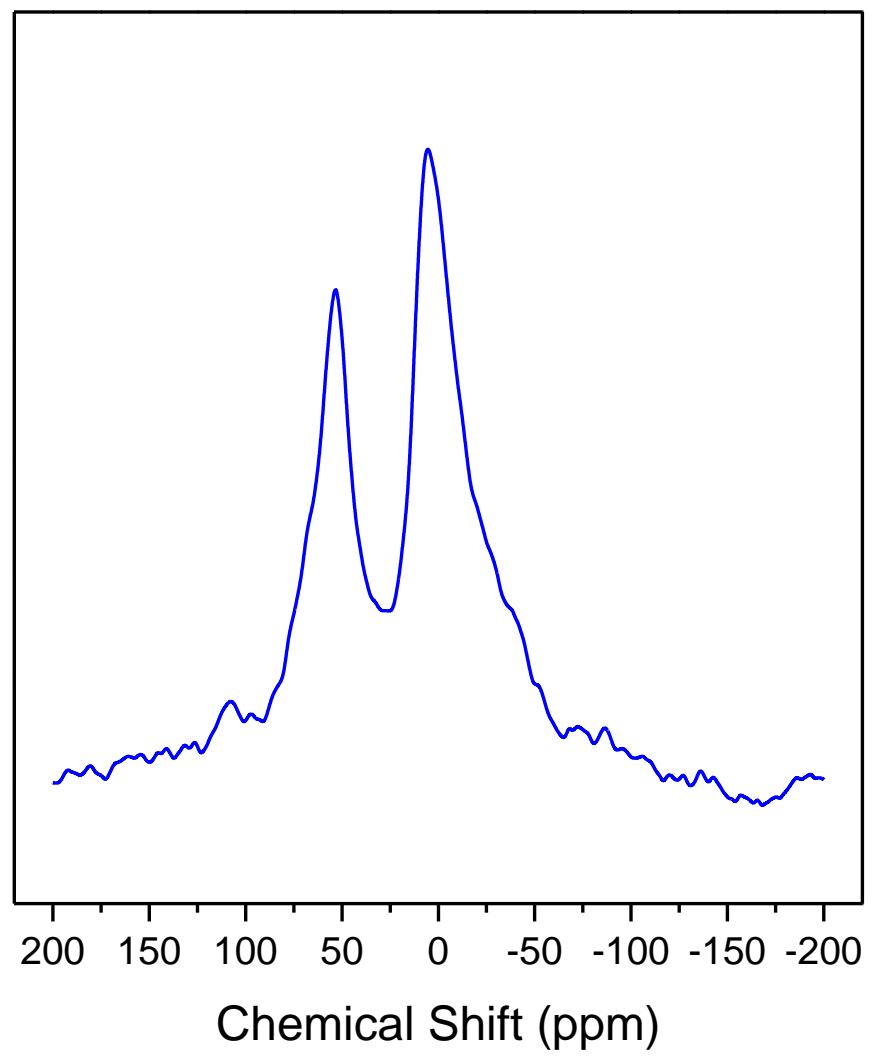

Fig. 5. Solid-state ${ }^{27}$ Al NMR spectrum of the Al-substituted SBA-15 material. 


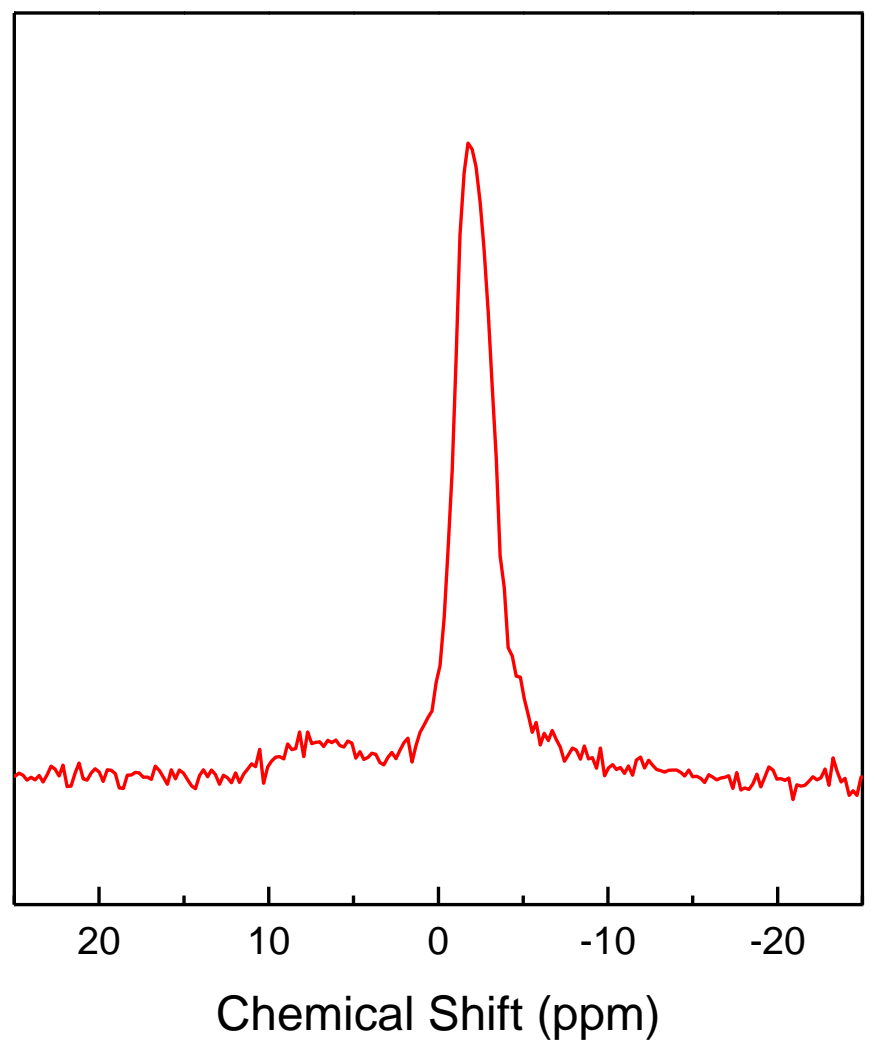

Fig. 6. Solid-state ${ }^{11}$ B NMR spectrum of the B-A3-SBA-15 material. 


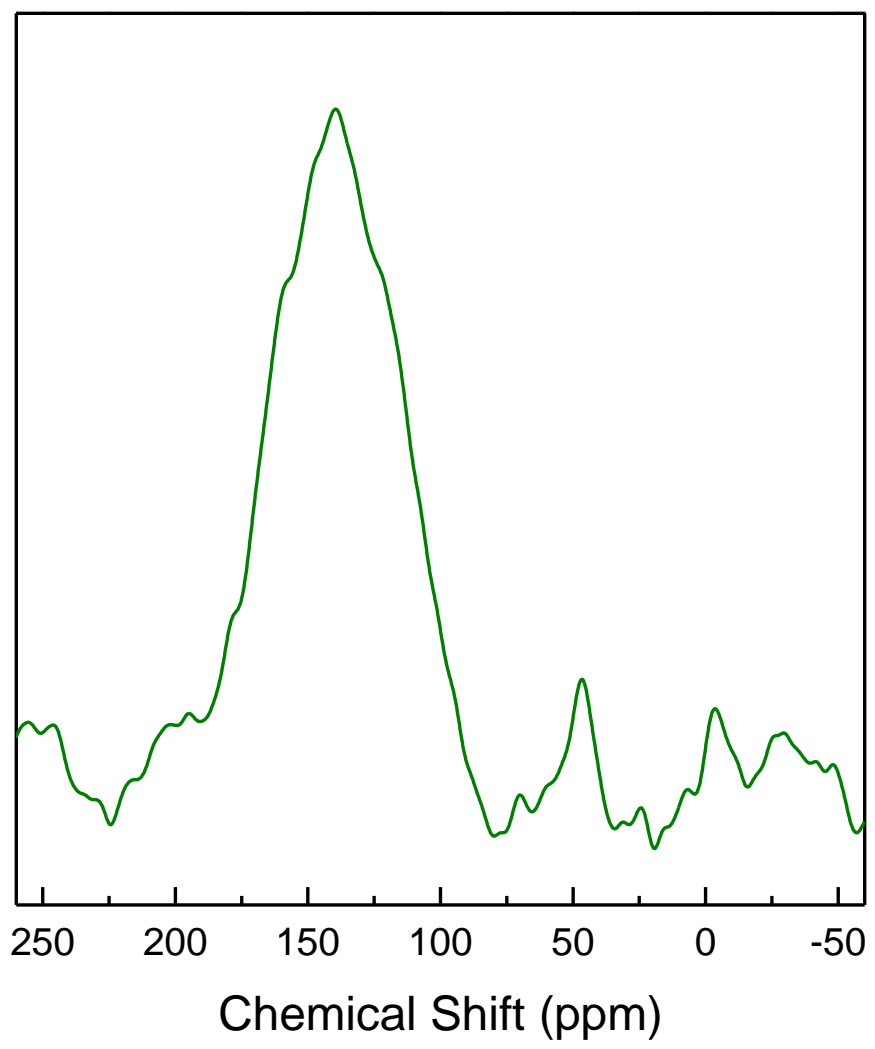

Fig. 7. Solid-state ${ }^{71}$ Ga NMR spectrum of the Ga-A3-SBA-15 material. 


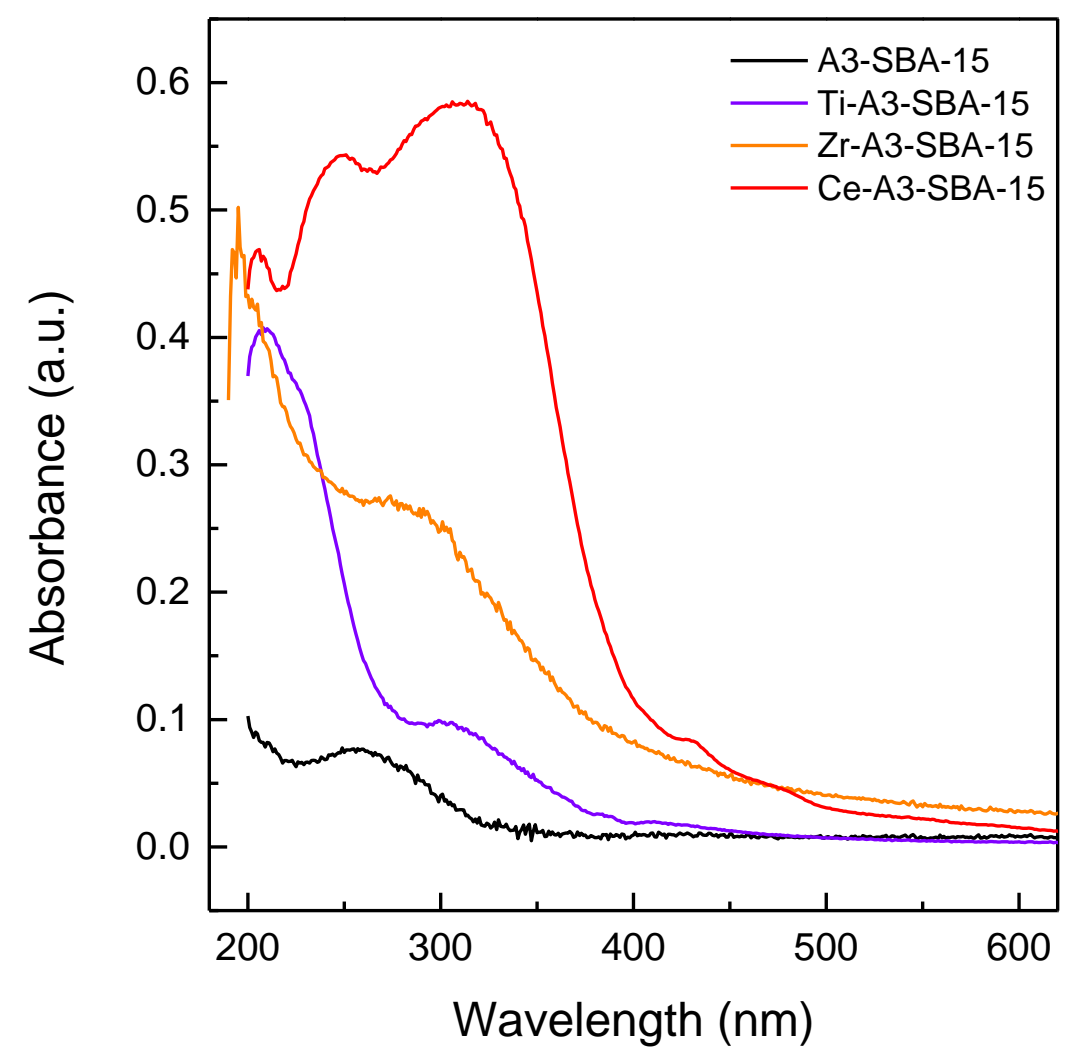

Fig. 8. Diffuse reflectance UV-Vis spectra of Ti-A3-SBA-15, Zr-A3-SBA-15, and Ce-A3-SBA15 materials. The standard A3-SBA-15 sample is shown for reference. 


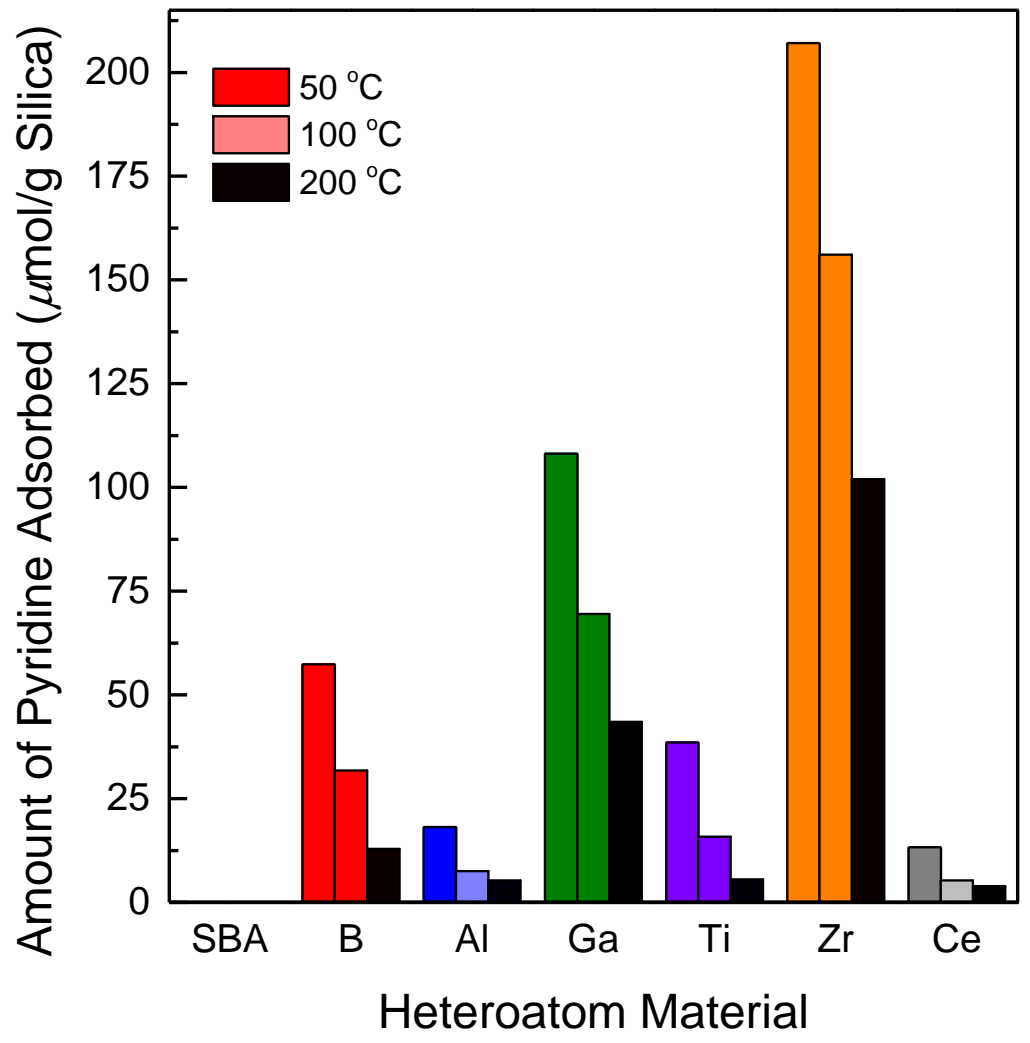

Fig. 9. Total amounts of acid sites (Brønsted and Lewis) for the six heteroatom materials and the standard A3-SBA-15 material for which only physisorbed pyridine was observed. The data represent the amounts of acid sites present after desorption of pyridine at various temperatures. For each material, the left bar refers to a desorption temperature of $50{ }^{\circ} \mathrm{C}$, the middle bar refers to $100{ }^{\circ} \mathrm{C}$, and the right bar refers to $200{ }^{\circ} \mathrm{C}$. Note that A3-SBA-15 had weakly physisorbed pyridine (see Fig. S2 in the Supporting Information) where weak interaction with surface silanols would be expected [58], indicative of very weak Brønsted acid sites. 


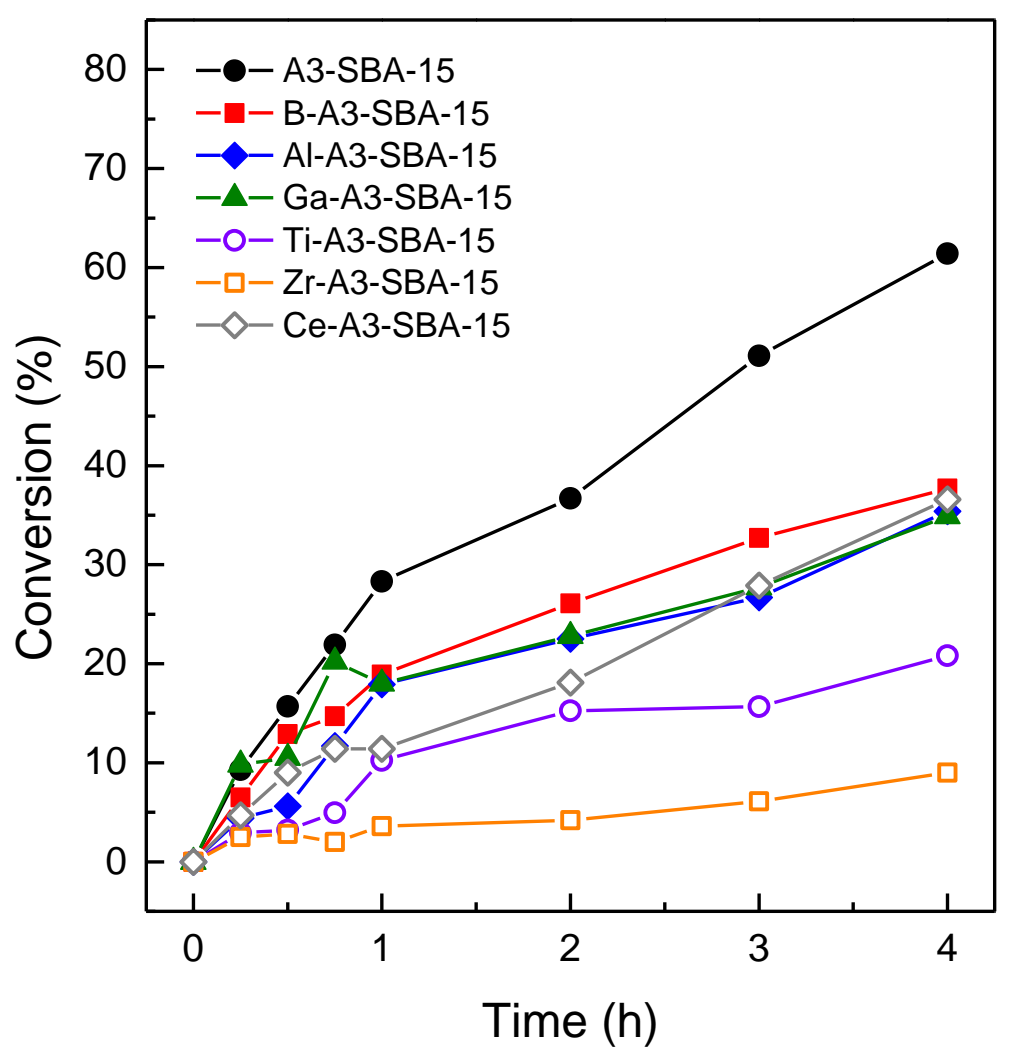

Fig. 10. Conversion of 4-nitrobenzaldehyde as a function of time for each of the heteroatom materials in the model aldol condensation. The conversion profile of A3-SBA-15 is provided for reference. 


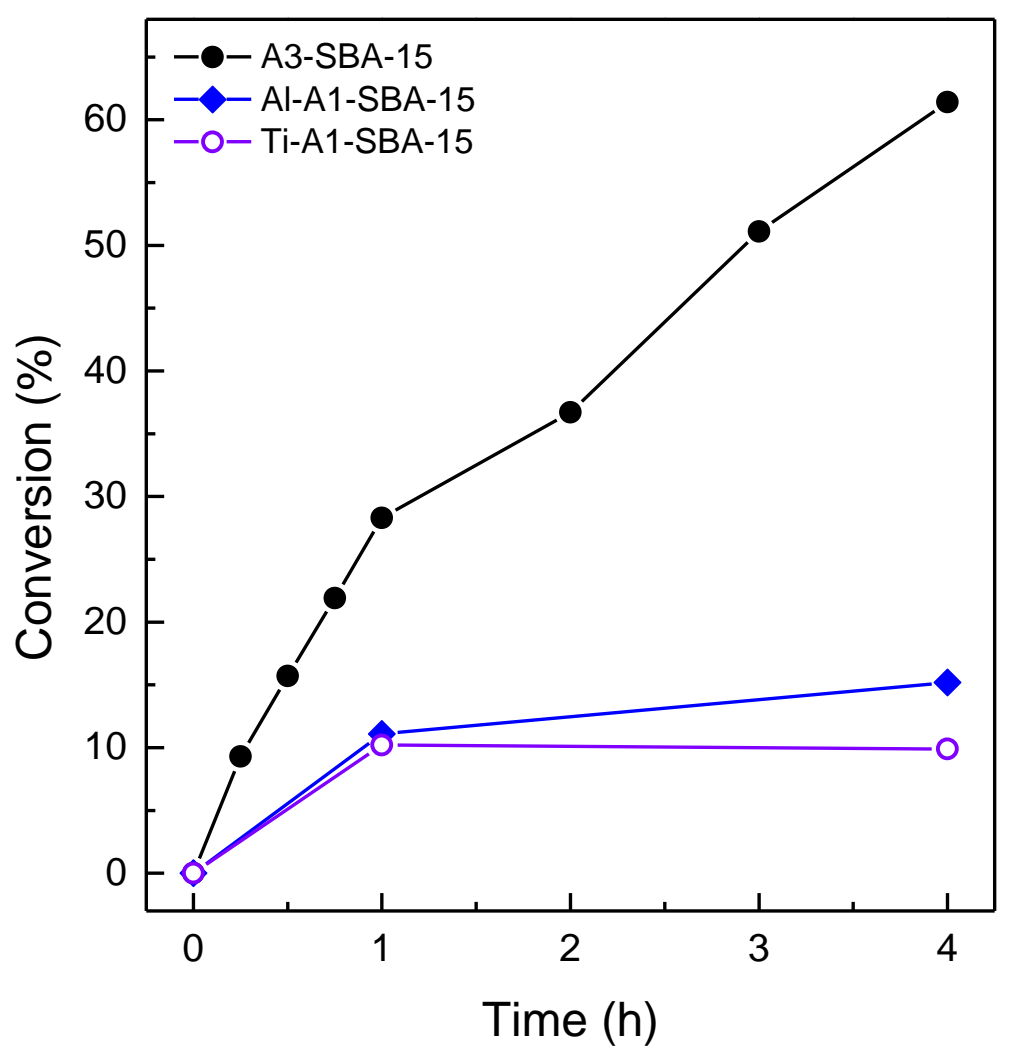

Fig. 11. Conversion of 4-nitrobenzaldehyde as a function of time for aminomethylfunctionalized materials Al-A1-SBA-15 and Ti-A1-SBA-15 in the aldol condensation. The conversion profile of A3-SBA-15 is provided for reference. 


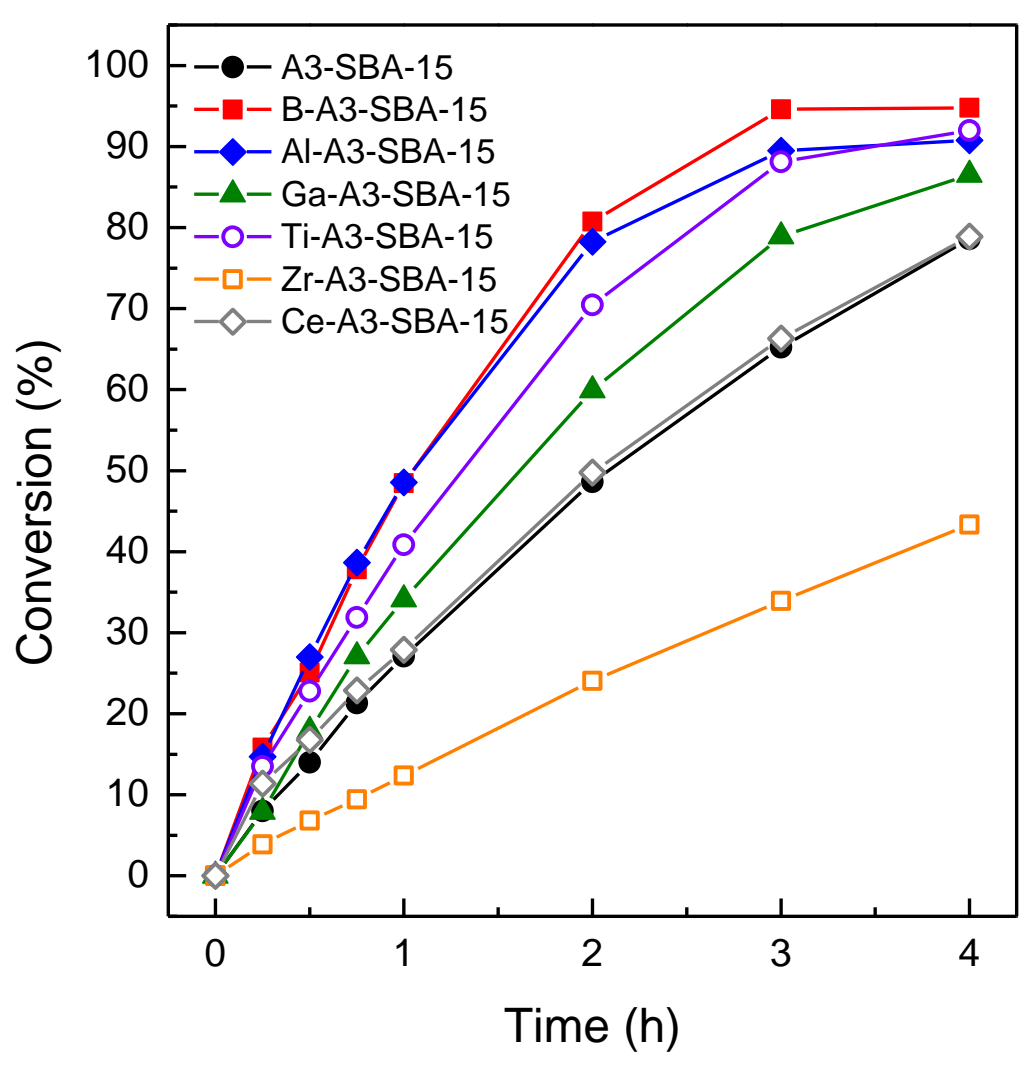

Fig. 12. Conversion of 4-nitrobenzaldehyde as a function of time for each of the heteroatom materials in the model nitroaldol condensation. The conversion profile of A3-SBA-15 is provided for reference. 


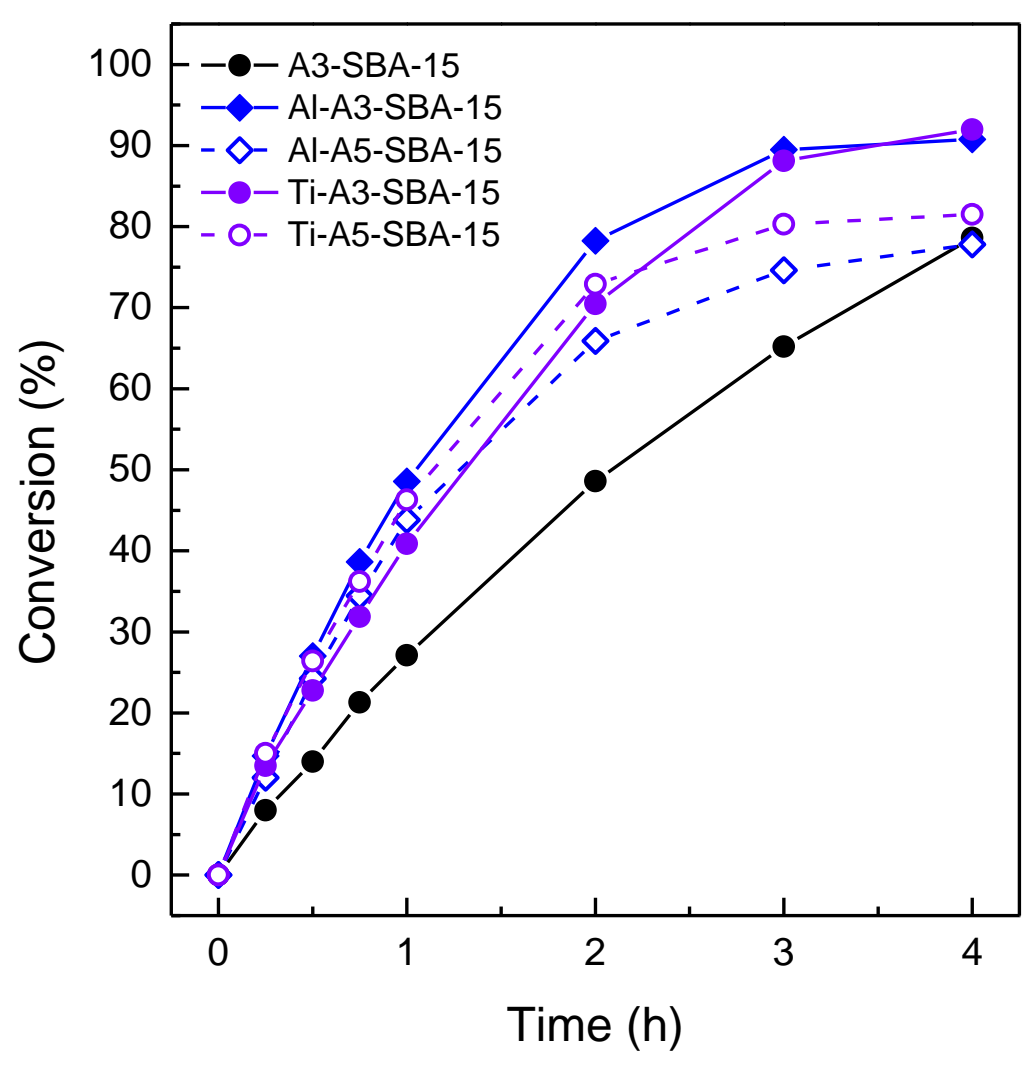

Fig. 13. Conversion of 4-nitrobenzaldehyde as a function of time for Al- and Ti-substituted materials functionalized with aminopentyl (A5) groups. The conversion profiles of A3-SBA-15, Al-A3-SBA-15, and Ti-A3-SBA-15 are provided for reference. 